\title{
Erica Xu
}

Hong Kong Baptist University

erica_xu@hkbu.edu.hk

Xu Huang

Hong Kong Baptist University

xuhuang@hkbu.edu.hk

Rongwen Jia

School of International Trade and Economics

University of International Business and Economics

Jiarw129@gmail.com

Jieying Xu

Zhejiang University of Finance and Economics

Janexu422@gmail.com

Wu Liu

The Hong Kong Polytechnic University

wu.liu@polyu.edu.hk

Les N. Graham

Durham University

l.n.graham@durham.ac.uk

Ed Snape

Hong Kong Baptist University

esnape@hkbu.edu.hk

Keywords: Abusive supervision, third-party observers, rivalry, schadenfreude, undermining, incivility,

and interpersonal deviance 


\title{
The "evil pleasure": Abusive supervision and third-party observers' malicious reactions toward victims
}

\begin{abstract}
We investigated how abusive supervision influences interactions between third-party observers and abused victims and hypothesized when and why third parties react maliciously toward victims of abusive supervision. Drawing on the theory of rivalry, we predicted that third-party observers would experience an "evil pleasure" (schadenfreude) when they perceive a high level of rivalry with the victims of abusive supervision and that the experienced schadenfreude then would motivate third parties to engage in interpersonal destructive behaviors (i.e., undermining, incivility, and interpersonal deviance) toward the victims. We further proposed that such malicious reactions would be attenuated if groups have a high level of cooperative goals. Results based on one experimental study and two time-lagged field studies lend support to our propositions.
\end{abstract}

Keywords: Abusive supervision, third-party observers, rivalry, schadenfreude, undermining, incivility, and interpersonal deviance 


\section{Introduction}

Abusive supervision, defined as supervisors' sustained display of verbal or non-verbal hostility toward followers (Tepper 2000), tends to undermine followers' well-being and harm their performance (Mackey et al. 2017). Although research has begun to explain how employees can shield and protect themselves from the destructive forces of abusive supervision (e.g., Nandkeolyar et al. 2014, Kiewitz et al. 2016, Wee et al. 2017), we know relatively little about how third-party observers react to abusive supervision (Mitchell et al. 2015). Several theoretical perspectives within the justice literature have focused on third parties' justice concerns and judgement in determining their reactions to victims' experienced injustice. Whereas research adopting the deontic justice theory (Folger 2001) has suggested that observers of mistreatment tend to experience social pains and feelings of injustice similar to those experienced by victims (e.g., Hatfield et al. 1978, Lind et al. 1998), the theory of belief in a just world (BJW, Lerner 1965) posits that people holding a strong belief in a just world are motivated to justify victims' aversive experience by blaming or derogating the victims (Lerner 1980, Furnham 2003). Recent studies have suggested that third-party observers may selectively apply justice rules to certain victims of mistreatment, depending on whether the victims fall within their scope of justice (Mitchell et al. 2015) or whether the observers have a positive (or negative) emotional orientation toward the victims of unfair treatment (Blader et al. 2013).

Albeit informative of these justice-related perspectives, the existing works have not yet considered the relationship characteristics between the observer and the victim. Relationship characteristics such as interpersonal rivalry may provoke observers' psychological processes beyond their justice concerns and judgement. Research on rivalry has suggested that people are motivated to do whatever is needed to beat their rivals (Kilduff et al. 2016), even if this feeling of winning is gained through passively seeing their rivals suffer. There is evidence that observers experience a sense of pleasure at victims' aversive experiences and even derogate victims who are their rivals, because through downward social comparison, rival victims' ordeals induce observers' feelings of superiority (Smith 2013). Hence, drawing from the theory of rivalry (Kilduff et al. 2010) and associated social comparison logics (Festinger 1954, Buunk and Gibbons 2007), we depart from the previous 
justice-related perspectives to contend that third parties may react maliciously to victims of abusive supervision when the observer has a rivalry relationship with the victim, because rivals tend to derive and exploit social comparison advantages resulted from abusive supervision of their opponents.

Rivalry refers to an individual's perception of an established competitive relationship between herself and a specific and identifiable opponent (Kilduff et al. 2010). This rivalry relationship tends to generate a sustained psychological desire for her to outperform the targeted opponent (Kilduff 2014). We propose that when a dyadic relationship between an observer and a victim is characterized by a high rather than low level of rivalry, observing abusive supervision of the victim may activate the observer's "evil pleasure," referred to in German as schadenfreude, which then leads the observer to engage in interpersonal destructive behaviors. such as undermining, incivility, and deviance, targeted at the victim, as a way to reinforce the observer's comparison advantages over the rival victim. We further propose that having cooperative goals may hinder third parties from engaging in downward comparisons with rival victims, and thus may moderate the interactive effect of observed abusive supervision and rivalry on third parties' experienced schadenfreude and exhibited destructive behaviors toward the victims. Figure 1 illustrates the proposed model.

Our study makes four theoretical contributions. First, previous research has relied mainly on the justice-based perspective to explicate third parties' failure to empathize with victims of workplace mistreatment. We offer a new explanatory perspective based on the theory of rivalry (Kilduff et al. 2010). We suggest that because organizations are fertile environments for generating rivalry and social comparison, third parties may react maliciously to victims of abusive supervision because of social comparison advantages obtained by observing the aversive experiences of victims who are their rivals at work. Second, our study contributes to the rivalry literature by suggesting and examining a set of behavioral consequences of rivalry. That is, observing supervisors' mistreatment of rival colleagues may drive third-party observers to inflict further harm upon the victims, for example, by exhibiting social undermining, incivility, and interpersonal deviance toward the victims. Third, we also shed light on how to effectively reduce the adversarial effect of interpersonal rivalry on victims of abusive supervision by proposing group cooperative goals as a buffering factor. In the rivalry 
literature, rivalry tends to have both beneficial (i.e., motivation; Kilduff et al. 2010) and destructive functions (e.g., unethical behavior; Kilduff et al. 2016). Casting group cooperative goals as a group-level moderator not only suggests a possible practical solution to reduce the potential negative observer reactions toward victims of abusive supervision, but it also may suggest that group norms can greatly attenuate rivalry's destructive effect on team member interactions. Fourth, we contribute to the literature of schadenfreude by examining its behavioral consequences. Despite knowing how schadenfreude is induced, there is limited empirical evidence about the behavioral consequences of schadenfreude (van Dijk et al. 2015). Whereas prior neuropsychological studies have only demonstrated that schadenfreude leads to the willingness, intention, and potential of doing harm (e.g., Singer et al. 2006, Cikara et al. 2011), we attempt to directly examine the extent to which third parties' schadenfreude generated by their rivals' misfortune would drive them to further harm their rivals in the forms of social undermining, incivility, and interpersonal deviance.

\section{THEORY AND HYPOTHESES}

\section{Third-Party Reactions to Abusive Supervision}

Several theoretical perspectives offer insights into and explanations for third parties' reactions to coworker experienced mistreatment from their supervisors. According to Folger's (2001) deontic justice theory, since individuals hold a moral assumption that human beings should be treated fairly, observing or learning about behaviors violating the moral norms tend to trigger deontic emotions, such as anger, and drive individuals to act to restore fairness by either retaliating against the perpetrators or helping the victims (O’Reilly and Aquino 2011). This deontic justice proposition, however, is in stark contrast to the key proposition of BJW (Lerner 1965). BJW posits that people need to believe that they live in a world where people generally get what they deserve and deserve what they get (Lerner 1965, 1980). Others' experiences of injustice, such as deprivation or suffering, pose a threat to individuals' just world belief and personal control over one's own destiny. Thus, people holding a strong belief in a just world would tend to eliminate injustice by blaming or derogating the victims (Lerner 1980, Furnham 2003).

Scope of justice theory provides a more fine-grained prediction of how third parties react to 
victims of abusive supervision. It posits that people have their own circle of moral regard that people use to include those persons whom they perceive as deserving fair treatment and feel obligated to apply moral rules to (Opotow 1990). In their study, Mitchell et al. (2015) found that when third parties hold a low level of moral exclusion belief (i.e., beliefs about whether another person deserves disrespectful or unfair treatment) about the target of abuse, observing abusive supervision evokes anger, which triggers supervisor-directed deviance and coworker support. By contrast, when moral exclusion beliefs are high, third parties experience feelings of contentment, which lead to coworker exclusion. In a similar vein, Blader et al. (2013) suggested that third parties' reactions to observed unfair treatment can be biased by their social emotions toward victims. They theorized and demonstrated that while a strong congruence of a social emotion (i.e. the extent to which one feels connected with and experiences emotions aligned with the target) leads third-party observers to judge the mistreatment of the target (i.e., under-disadvantage) as more unfair, a strong incongruence emotion drives third-party observers to perceive the mistreatment as more fair, and that justice judgment determines the third party observers' reactions.

At the core of the above theoretical perspectives, namely, deontic justice theory, theory of belief in a just world, scope of justice theory, and emotion-laden justice judgment, is the idea that third-party observers' reactions to mistreatment experienced by others are determined primarily by observers' concerns and assessments of fairness associated with victims' aversive experience. There are situations, however, where the victims' misfortunes may not necessarily involve justice concerns and assessments. For instance, committed baseball fans are often seen to be pleased when rival team members suffer severe injuries (Smith 2013). The players’ ordeals of injury are not necessarily caused by injustice or unfair treatment (e.g., they could just be accidents), and thus the baseball fans' malicious reactions cannot be fully explained by any of the above justice-based theoretical perspectives. Rather, the misfortune of the rival teams' players is likely to generate a social comparison advantage of the fans and induce their malicious pleasure of foreseeing a greater chance of winning (Smith 2013).

Therefore, departing from the justice-oriented perspectives, we propose a new approach to 
explaining third-party observers' reactions toward mistreatment of their coworkers. Drawing from the theory of rivalry (Kilduff et al. 2010, Kilduff 2014, Kilduff et al. 2016, Kilduff and Galinsky 2017), we contend that as the competitive context in organizations tends to foster interpersonal rivalry between interacting employees, third-party observers' malicious reactions to the misfortunes of coworkers may well be caused by interpersonal rivalry relationships. Indeed, recent social network research has suggested that to have a more complete understanding of the triadic relationships among the target, the actor, and the observer, one should take into consideration the rivalry relationships embedded in social networks (Westaby et al. 2014).

\section{The Role of Interpersonal Rivalry}

Life is a competitive game, and the workplace is potentially a theatre for this game (e.g., Bettenhausen and Murnighan 1991, Brown et al. 1998, Tauer and Harackiewicz 2004). In general, people are tuned into competition and have evolved to be alert to how well they are doing relative to others (Kilduff et al. 2010, Smith 2013). Individuals' history of competition at work may have evolved into a focus on a specific and identifiable opponent and winning against this particular opponent is of paramount importance (Kilduff et al. 2010, Kilduff 2014, Kilduff et al. 2017). This relationship characteristic is referred to as rivalry, defined as "a subjective competitive relationship that an actor has with another actor that entails increased psychological involvement and perceived stakes of competition for the focal actor, independent of the objective characteristics of the situation” (Kilduff et al. 2010, p. 945). Although rivalry depicts a competitive psychological orientation toward a particular opponent, rivalry and dislike are orthogonal (Kilduff 2014; Kilduff et al. 2016). Rivals are not necessarily enemies of each other. Their opponents may like or dislike them (Kilduff 2014). Previous research has identified several main predictors of rivalry formation, such as similarity between actors (e.g., similarity in ranking), repeated competition, and competitiveness in terms of the historic match-ups between actors (Kilduff et al. 2010).

Although rivalry and competition are often used interchangeably in the literature, recent research has differentiated rivalry from competition (Kilduff et al. 2010, Kilduff 2014). Competition refers to a state or a situation of opposing goals or contested resources (Deutsch 1949; Kohn 1992). It 
exists when people vie for scarce resources; and it ends when the competing situation is over. Rivalry, however, involves a relationship and history that goes beyond the current state of conflict over tangible resources. Rivalry is both relational and psychological. Not only does the actor have a specific and identifiable opponent, but also such a rivalry relationship exists in the actor's mind regardless the availability of objective rewards. It directs a competitive mind-set to outperform a targeted opponent, even when objective rewards are not at stake. Competition manifests on competing for "something," in which actors matter less. Actors may be different across competitions. In contrast, rivalry manifests on competing against "someone”; the actors matter the most even when "something" is absent.

In the organizational context, employees tend to constantly evaluate and compare themselves with each other, in regard to performance, achievements, and other important outcomes relative to their own (e.g., Lam et al. 2011, Kim and Glomb 2014), and employees are likely to identify some coworkers as their rivals (Menon and Blount 2003, Menon et al. 2006, Kilduff et al. 2010, Westaby et al. 2014). Rivalry provides a powerful motivational force in driving individuals' effort-based performance (Kilduff et al. 2010). Rivalry, however, has a corruptive force in alluring individuals to do "whatever it takes" to defeat a rival, such as deception, cheating, and sabotage (Ku et al. 2005, Tully 2006, Malhotra et al. 2008, Kilduff et al. 2016). This negative implication of rivalry may have a profound influence on how an observer reacts to the abusive supervision of a rival coworker.

\section{Abusive Supervision, Rivalry, and Schadenfreude}

Observing the abusive supervision of a coworker is likely to elicit a range of emotions, such as fear or anxiety, as observers may worry that they will become victims too (Peng et al. 2014). Such emotions are self-focused and may lead observers to engage in self-protective behaviors from abusive supervision in the future, but these emotions are unlikely to direct observers' reactions toward the victims of abusive supervision. Third-party observers may also experience another type of emotion interpersonal emotion, which is the affective state toward the victims (e.g., Hareli and Parkinson 2008, Burnett et al. 2009, Blader et al. 2013). We suggest that observing a rival coworker's experience of abusive supervision may induce an interpersonal emotion of schadenfreude, which in turn provokes 
destructive behaviors toward the victim. Schadenfreude refers to the experience of pleasure at another's misfortune (James et al. 2014). It is a typical emotional outcome of downward social comparison (Smith 2000), and it captures third parties' pleasure of social comparison benefits and superiority against the target.

Rivals are constantly comparing themselves to each other. The abusive supervision of one's rival presents a situational opportunity for the focal actor to get ahead because of the rival's loss, and thus it elicits an irresistibly pleasant sensation that aligns with "winning," even though it is passively experienced in seeing the rival suffer (Leach et al. 2003). First, contemporary psychology suggests that people are motivated to feel good about themselves and that this motivation constitutes a key drive of human behavior (Baumeister 1991; Brown and Dutton 1995; Sedikides and Strube 1997; Tesser et al. 1988). People are able to feel good about themselves when they discover that they are doing better than others (van Dijk et al. 2009; Wills 1981). Misfortunes happening to others, especially one's rivals, help generate this positive feeling. Social comparison benefits accruing from the misfortunes befalling rivals give people a sense of superiority. Thus, when third parties observe the abusive supervision of their rivals, they are likely to feel pleasure, because the suffering of their rivals provides them with psychological gains resulting from uplifting comparison benefits (van Dijk et al. 2015). Second, third-party observers may also feel pleasure about the potential instrumental gains from the abusive supervision of a rival. In organizations, leaders control most of the scarce and valuable resources for which employees are competing. Leaders' approval and disapproval of employees' rivals may significantly influence whether they can gain an edge over their rivals. Third-party observers are thus likely to anticipate instrumental gains out of their rivals' downfall caused by abusive supervision. As a result, third-party observers are more likely to experience an irresistible "evil” pleasure at their rival's misfortune. In contrast, when observers do not perceive victims of abusive supervision as rivals, they are less likely to feel pleasure, because observing the abusive supervision of a non-rival coworker provides fewer psychological and instrumental gains. Hence, we predict:

Hypothesis 1: The relationship between observed abusive supervision of a victim and schadenfreude is moderated by perceived rivalry towards the victim, such that the relationship is 
positive when rivalry is high rather than low.

\section{Schadenfreude and Interpersonal Destructive Behaviors toward Abused Coworkers}

Schadenfreude is an evolved psychological mechanism. It is not a person's absolute level of success that triggers schadenfreude; rather, schadenfreude is the outcome of a desire for "others must fail” (Jones 2013, Smith 2013). Through a social comparison lens, a rival is often seen as threatening to one's ego (Locke 2007, Tesser 1988), and thus people tend to minimize such threats through defensive behaviors, such as harming, when there is an opportunity (e.g., Lam et al. 2011). When observing a rival member being abused by a supervisor, a focal individual may feel delighted, not only because they feel better about themselves through downward comparison, but also, because they see it as an opportunity to defeat the rival. Supervisors often set the norms for acceptable and expected behaviors, and subordinates often follow their lead. Seeing one's supervisor abuse a rival member provides an opportunity for the third-party observer to imitate the supervisor's abusive behavior (e.g., Bandura, 1977). Thus, feelings of schadenfreude out of rivals’ setbacks may drive focal individuals to reinforce their social comparison advantages and superiority by inflicting further harm to the rivals (Cikara et al. 2011, Cikara and Fiske 2011). Schadenfreude, as described by Smith (2013, p. 48) is "as natural as it is to feel, may be a kind of gateway drug, closing the door on compassion and encouraging darker emotions and actions.” Enjoying rivals’ misfortunes may evolve into individuals' longing for more misfortune and the willingness to create it by themselves (Smith 2013). Indeed, recent neuropsychological research has demonstrated that the neural activation associated with schadenfreude in response to a rival's misfortune is related to the endorsement of harming behavior (e.g., Singer et al. 2006, Takahashi et al. 2009, Cikara et al. 2011). There is evidence that pleasure evoked from others' misfortune tends to translate into direct derogation of the source of schadenfreude (Spears and Leach 2004). We therefore suggest that an observer's feelings of schadenfreude induced by social comparison advantages over a rival's misfortune are likely to lead the observer to engage in malicious and destructive behaviors toward the rival. To capture interpersonal destructive behaviors in the workplace, we focus on social undermining, incivility, and interpersonal deviance targeted at victims of abusive supervision, because while displaying incivility 
to the rival helps reinforce the observer's sense of superiority, interpersonal undermining and deviance behaviors are likely to strengthen the observer's opportunity to get ahead. Hence, we predict:

Hypothesis 2: Perceived rivalry moderates the indirect effect of observed abusive supervision of a victim on a third-party observer' interpersonal destructive behaviors (undermining, incivility, and deviance) toward the victim via the observer's schadenfreude, such that a positive indirect effect occurs under high rather than low perceived rivalry.

\section{The Role of Group Cooperative Goals}

Above we argued that the psychological and instrumental benefits obtained through downward social comparison explain the positive effect of observed abusive supervision on third parties' feelings of schadenfreude under the condition of high rivalry. We further argue that group cooperative goals, referring to members' shared belief that their individual goal achievements are positively related (Johnson and Johnson 1989, Tjosvold et al. 2004), may regulate the extent to which individuals engage in detrimental social comparisons with rival victims (Lam et al. 2011). Note that the prerequisite for rivalry formation between actors is often independent of group norms. For example, an identified predictor of rivalry is similarity between actors, such as the same position or ranking (Kilduff et al. 2010).

In a group with high cooperative goals, members' goals are integrated with each other and their own gains and losses tend to depend on the gains and losses of other members, respectively. In such a context, group members tend to develop shared identification and togetherness, which may promote the assimilative approach and suppress the contrast approach to social comparison (Bunnk et al. 2005). Social comparison research has suggested that assimilative downward comparison (i.e., assuming similarity in an unfortunate fate) is less likely to induce feelings of schadenfreude than contrast downward comparison (i.e. assuming dissimilarity in an unfortunate fate). Hence, in a highly cooperative context, observing the downfall or misfortune of a rival in the group is less likely to induce social comparison benefits for observers, because the loss of the rival may not generate psychological and instrumental gains for observers. In contrast, in groups with a low level of cooperative goals, members' goals are not aligned, but instead are independent from each other (Johnson and Johnson 1989, Tjosvold et al. 2004). A low cooperative context may reinforce contrast downward comparison 
(Bunnk et al. 2005) and thus tends to boost the psychological and instrumental benefits of third-party observers resulted from the downfall of their rivals.

Taken together, the amplifying effect of interpersonal rivalry on the positive link between abusive supervision of a rival and the third party observer's schadenfreude is likely to be weaker in groups with high cooperative goals, because a high cooperative context tends to promote assimilative approach to social comparison. In contrast, interpersonal rivalry should have a stronger and positive moderating effect on the relationship between observed abusive supervision and schadenfreude in groups with low cooperative goals, because a low cooperative context is likely to fuel downward contrastive comparison. We further predict that the indirect effect of observed abusive supervision on interpersonal destructive behaviors via schadenfreude is jointly moderated by a rivalry relationship with the victim and group cooperative goals.

Hypothesis 3: Group cooperative goals and perceived rivalry jointly moderate the relationship between observed abusive supervision of a victim and a third-party observer's schadenfreude: The positive relationship is strongest when group cooperative goals are low and perceived rivalry is high.

Hypothesis 4: Group cooperative goals and perceived rivalry jointly moderate the indirect effect of observed abusive supervision of a victim on a third-party observer's interpersonal destructive behaviors (undermining, incivility, and deviance) toward the victim via the observer's schadenfreude, such that the positive indirect effect is the strongest when group cooperative goals are low and perceived rivalry is high.

We conducted three studies to progressively test our hypotheses. Study 1 is an experimental study using undergraduate students to examine Hypotheses 1 and 2. In Study 2, to increase the external validity and test all the hypotheses, we conducted a time-lagged field study. In Study 3, to address the limitations of Study 2 (e.g., lack of control variables) and replicate the findings, we examined our hypotheses by using another time-lagged field data.

\section{STUDY 1: METHODS}

\section{Design, Task, and Manipulations}

Full-time undergraduate students $(N=156)$ from a university located in the north of Mainland China participated in Study 1. The average age of participants was 20.88 years (SD $=1.02$ ), and 22\% 
of them were women. We used a scenario procedure to manipulate the independent variables. We randomly assigned participants to one of the four conditions in a 2 (observed abusive supervision vs. observed non-abusive supervision) x 2 (rivalry vs. non-rivalry) between-subject design. Forty participants were assigned to the condition of observed abusive supervision and rivalry, 38 participants were assigned to the condition of non-abusive supervision and rivalry, and 39 participants were assigned to each of the other two conditions. Schadenfreude, undermining, incivility, and deviance were the dependent variables. Participants were informed that the task in the experiment was to read a brief, hypothetical scenario and answer a number of questions regarding it.

The basic scenario description was identical across the four experimental conditions. Participants were asked to play the role of a student who had enrolled in an Entrepreneurship course taught by Professor Zhang from the Department of Management. Students registered in this course were required to submit a proposal of establishing a start-up firm at the end of the semester as the major part of an individual performance assessment. Professor Zhang gave comments and suggestions to the work of every student in the class. The scenario described an interaction between Professor Zhang and one of the students, Xiaoping Li (a gender neutral name), which the participants observed in the class. This situation was used to manipulate the independent variables, as outlined below.

\section{Manipulations}

Manipulating observed abusive supervision. In all four conditions, participants read that in today's class, when Xiaoping Li reported the progress of the proposal, Professor Zhang criticized Xiaoping's proposal. In the observed abusive supervision condition, we consulted with the measurement of abusive supervision (Tepper 2000) and used several items that could be planted in the scenario including “ridicules him/her," "doesn’t give him/her credit for jobs requiring a lot of effort," "makes negative comments about him/her to others," "tells him/her that his/her thoughts or feelings are stupid," and "puts him/her down in front of others." We modified those items and integrated them into the scenario of observed abusive supervision in the following:

Professor Zhang criticized Xiaoping's proposal, and ridiculed that his/her idea was not practical and came out of his/her groundless fantasies and imagination. Although Xiaoping had put a lot of effort into completing and submitting the proposal in such a short time, Professor Zhang did not give any credit or 
show appreciation. In front of the whole class, Professor Zhang declared that Xiaoping's proposed ideas were stupid and made negative comments on some other problems of the proposal.

The non-abusive supervision condition reads as follows:

Professor Zhang criticized Xiaoping's proposal and pointed out that his/her idea was not practical and lacked facts and evidence to support the proposed ideas. Yet, Professor Zhang gave credit and showed appreciation for Xiaoping's effort in completing and submitting the proposal in such a short time. In front of the whole class, Professor Zhang stressed that Xiaoping's proposal still had a lot of room for improvement and offered comments on some other problems of the proposal in a constructive way.

Manipulating rivalry. We followed Kilduff et al. (2016) to manipulate the rivalry relationship. Participants in the rivalry condition read that they had a long history of competing with Xiaoping Li in many different contexts, such as competing against Xiaoping for the best student award, the election of the president of the Student Union, opportunities for exchange at top universities abroad, an internship position in a leading firm, and so forth. Participants and Xiaoping had been evenly matched over the years, with neither side ever taking a decisive lead. As a result of this, participants "feel a good deal of rivalry towards Xiaoping" and participants "get the impression that these feelings are mutual.” Participants in the non-rivalry condition read that they did not have a history of competition with Xiaoping. Participants had not yet experienced any direct competition with Xiaoping. As a result, participants “do not feel any rivalry toward Xiaoping.”

\section{Measures}

As scales in our survey were originally developed in English, we followed the translation and back-translation procedure to produce a Chinese version of the scales (Brislin et al. 1973).

Schadenfreude. We measured schadenfreude with a four-item, seven-point scale developed by Leach et al. (2003). Participants were asked to rate the extent to which they felt each emotion (satisfied, relieved, happy, and schadenfreude) as a consequence of Professor Zhang's treatment of Xiaoping in the described scenario. Note that, in Chinese language, there is an exact counterpart of the German word "schadenfreude.” Right after we asked participants the five-item manipulation check questions of observed abusive supervision, we immediately asked respondents to rate the extent to which “you feel happy with the way Professor Zhang treated Xiaoping in today’s class” ( 1 = not at all; 
$7=$ very much; $\alpha=.88)$.

Undermining. We measured the behavioral intention to undermine by using a two-item, seven-point scale from Duffy et al. (2006). The items are "(In the future, you will) sometimes make it difficult for Xiaoping to do his/her job well," and “(In the future, you will) sometimes act like you dislike or disapprove of Xiaoping.” (1 = very unlikely; 7 = very likely; $\alpha=.69)$.

Incivility. We measured incivility using five items from the incivility scale developed by Cortina et al. (2001). We dropped two items that did not fit the context (e.g., "address Xiaoping in unprofessional terms, either publicly or privately”). Sample items include: "put Xiaoping down or are condescending to him/her," and "make demeaning or derogatory remarks about Xiaoping." $(1$ = very unlikely, 7 = very likely; $\alpha=.74)$.

Interpersonal deviance. We measured interpersonal deviance by using five items from the interpersonal deviance scale developed by Bennett and Robinson (2000). We dropped two items (e.g., "make an ethnic, religious, or racial remark") from the original scale, because they did not fit the context. Sample items are: "make fun of Xiaoping in front of others," "act rudely toward Xiaoping," and "publicly embarrass Xiaoping” ( 1 = very unlikely, 7 = very likely; $\alpha=.87)$.

Control variables. We controlled for belief in a just world, as such a belief is likely to influence third parties' reactions to observed abusive supervision (e.g., Lerner 1980). We measured belief in a just world using a six-item, five-point scale developed by Dalbert (1999). A sample item is "I believe that, by and large, people get what they deserve” ( $1=$ strongly disagree, $5=$ strongly agree, $\alpha=.77)$. We also considered controlling for the emotions of contentment and fear. First, contentment has been shown to serve as a mediator in the relationship between observed abusive supervision and coworker exclusion (Mitchell et al. 2015). We thus needed to partial out the effect of contentment. We used a three-item, five-point scale from Mitchell et al. (2015; “content," "serene,” and "peaceful,” $\alpha=.87$ ). In addition, observing the abusive supervision of a coworker may elicit other emotions, such as fear, that may affect how they react to it. We thus asked participants to respond to one item of "fear" as the consequence of observing the way Professor Zhang treated Xiaoping in class and controlled for it in our analyses. Note that, our results remained unchanged when excluding any or all of the three control 
variables.

\section{STUDY 1: RESULTS AND DISCUSSION}

\section{Manipulation Checks}

Five items assessed observed abusive supervision (e.g., "Professor Zhang ridiculed Xiaoping's proposal in class," and "Professor Zhang made negative comments on Xiaoping's proposal in front of the class”; $\alpha=.94 ; \mathrm{M}=3.10, \mathrm{SD}=1.91$ ) and four items assessed perceived rivalry (e.g., "You considered Xiaoping as your rival,” [Kilduff 2014]; 1 = strongly disagree; 7 = strongly agree; $\alpha=.77 ; \mathrm{M}=3.94, \mathrm{SD}=1.31$ ). Results indicated that Xiaoping was perceived as being more abused in the abusive condition $(\mathrm{M}=4.54, \mathrm{SD}=1.70)$ than in non-abusive condition $(\mathrm{M}=1.69$, $\mathrm{SD}=.59, \mathrm{p}<.001)$ and that the participants in the rivalry condition felt a higher level of rivalry toward Xiaoping $(\mathrm{M}=4.63, \mathrm{SD}=.93)$ than did the participants in the non-rivalry condition $(\mathrm{M}=3.19$, $\mathrm{SD}=1.26, \mathrm{p}<.001)$. Table 1 presents the correlation coefficients of the variables.

\section{Hypothesis Testing}

We used a 2 x 2 ANOVA to examine the two-way interactive effect of observed abusive supervision and perceived rivalry on third parties' schadenfreude (Hypothesis 1). Results indicated that the interaction between observed abusive supervision and perceived rivalry was significantly related to schadenfreude $(F=13.26, \mathrm{p}<.001)$. The pattern of the significant interactive effect of observed abusive supervision and perceived rivalry on schadenfreude is plotted in Figure 2. As shown, when observing the Professor's abusive treatment of Xiaoping, participants in high rivalry condition $(M=2.65, S D=1.19)$ felt more schadenfreude than did those in the low rivalry condition $(M=1.73$, $\mathrm{SD}=1.04, \mathrm{p}<.001)$. Moreover, when participants feel a strong rivalry relationship with Xiaoping, participants in the observed abusive supervision $(\mathrm{M}=2.65, \mathrm{SD}=1.19)$ showed significantly higher level of schadenfreude than participants in non-abusive supervision condition $(\mathrm{M}=2.09, \mathrm{SD}=.87$, $\mathrm{p}$ $<$.05). Hence, Hypothesis 1 was supported.

Insert Table 1 and Figure 2 about here

We then tested Hypothesis 2, the moderated mediation model. We used path analytic 
procedures (Edwards and Lambert 2007, Preacher et al. 2007) and conducted a bootstrapping analysis to assess the significance of indirect effects (Shrout and Bolger 2002). We used Model 7 in the SPSS PROCESS macro (Hayes 2013) to test the first-stage moderated mediation. In specific, we estimated the conditional indirect effect of observer abusive supervision on dependent variables through schadenfreude both at high and low levels of rivalry, using unstandardized coefficients and bootstrapping with 5,000 resamples to place 95\% confidence intervals around estimates of the indirect effects. The results of the bootstrapping indicated that under the high rivalry condition, observed abusive supervision had a significant and positive indirect effect on undermining through schadenfreude (indirect effect $=.13 ; 95 \%$ CI $[.023, .271]$ ). In contrast, under the low rivalry condition, the indirect effect of observed abusive supervision on undermining through schadenfreude was not significant (indirect effect $=-.05 ; 95 \%$ CI $[-.145, .017]$ ). Regarding incivility, under the high rivalry condition, the indirect effect was significantly positive (indirect effect $=.08 ; 95 \%$ CI $[.020, .167]$ ). Under the low rivalry condition, the indirect effect was significantly negative (indirect effect $=-.04$; 95\% CI [-.099, -.000]). Regarding deviance, under the high rivalry condition, there was a significant and positive indirect effect on deviance through schadenfreude (indirect effect $=.06 ; 95 \% \mathrm{CI}$ $[.017, .120])$, whereas the indirect effect was not significant under the low rivalry condition (indirect effect $=-.02$, $[-.058, .007])$. Hence, Hypothesis 2 was supported.

In Study 1, we found support for the moderating role of rivalry on the relationship between observed abusive supervision and schadenfreude and also the conditional indirect effect of observed abusive supervision on interpersonal destructive behaviors. An inherent limitation of scenario studies, however, is that we can only test behavioral intentions and not actual behaviors. To address this limitation and also to test all the hypotheses, we conducted two independent field studies.

\section{STUDY 2: METHODS}

\section{Sample and Procedures}

We conducted an on-site survey at a state-owned bank in China. Participants were front-line employees, including sales representatives for retail banking and tellers for service counters. We collected data in two waves using a round-robin design, in which group members rated all other 
members of their group (Warner et al. 1979). In so doing, specific actors (i.e., observers of abusive supervision) and targets (i.e., victims of abusive supervision) could be matched in the data analyses. In a work group with four members, for example, member M1 rated the extent to which he/she had observed the group leader abusing M2, M3, and M4, and his/her interactions with M2, M3, and M4, respectively. Then member M2 rated members M1, M3, and M4, and so on. At Time 1, we collected data on the control variables, and the self-rating of observed abusive supervision, perceived rivalry, group cooperative goals, and schadenfreude. To illustrate, M1 reported the observed abusive supervision of M2, the degree of perceived rivalry with M2, cooperative goals in the group, and felt schadenfreude toward M2. At Time 2, three months later, we measured peer ratings of interpersonal destructive behavior. In other words, we asked M2 (a peer of M1) to report on the interpersonal destructive behavior received from M1. This study design was intended to reduce common method bias by collecting data from different sources at different points of time (Podsakoff et al. 2003).

We distributed surveys to 140 employees from 31 work groups, with an average group size of 10 members. We randomly selected four to five members from each group to participate in the survey. Respondents were briefed before the survey and assured that their responses would be kept confidential. Respondents returned the surveys to the researchers immediately upon completion. After matching the responses from Time 1 and Time 2 and excluding incomplete dyads, the final sample comprised 120 employees from 30 work groups, with 376 usable dyadic relations. The effective response rate was $86 \%$. Forty percent of the respondents were men, and $95 \%$ had received a college education or above. The mean age of the respondents was 27 years, and the mean organizational tenure was 3 years.

\section{Measures}

Observed abusive supervision. To reduce rater fatigue in a round-robin assessment, we used Mitchell and Ambrose's (2007) five-item scale. Each respondent was asked to rate the extent to which the five types of abusive supervision behaviors were observed as representative of their supervisor's behavior toward one particular group member in the past three months. One sample item is "My boss put $[\mathrm{X}]$ down in front of others.” The term $[\mathrm{X}]$ was replaced by the name of a group member. The five 
items of abusive supervision were subsequently repeated for all members of the group $(1=$ strongly disagree, 7 = strongly agree; $\alpha=.96)$.

Perceived rivalry. We extended Kilduff et al.’s (2010) original single-item measure into a three-item measure. In a dyadic relationship, the actor and the target could have different perceptions of rivalry (Kilduff et al. 2010). Given that the actors' (i.e., third-party observers') perceptions of rivalry are critical in determining the extent to which actors feel schadenfreude toward victims of abusive supervision, we adopted the actors' perspective. We asked respondents to indicate the extent to which they viewed other group members as rivals to themselves. Items include (1) "I consider him/her as my rival at work,” (2) “He/she is my rival in terms of performance,” and (3) "Overall, he/she is my rival at work" ( $1=$ strongly disagree, $7=$ strongly agree, $\alpha=.94)$.

Group cooperative goals. We used a five-item, five-point scale developed by Tjosvold et al. (2004) to measure this variable. A sample item is "Our group members' goals go together" $(1=$ strongly disagree, $5=$ strongly agree; $\alpha=.89$ ). We calculated a single score for each group by aggregating the ratings of individual members. The intraclass correlation coefficients $\left(\mathrm{ICC}_{1}=.16, \mathrm{ICC}_{2}=.43\right)$ and the median within-group agreement value (Median $\left.\mathrm{r}_{\mathrm{wg}(\mathrm{j})}=.97\right)$ exceeded those typically recommended for aggregation (James 1982, James et al. 1984).

Schadenfreude. We used the same scale as that of Study 1 to assess schadenfreude (Leach et al. 2003; $\alpha=.96)$. Immediately after respondents rated the extent to which the supervisor exhibited abusive behaviors toward a particular group member, they were asked to rate the extent to which they felt the emotions (i.e., satisfied, relieved, happy, and schadenfreude) when they observed the above abusive behaviors toward this group member.

Interpersonal destructive behavior. We adapted measures from Duffy et al. (2006), Lam et al. (2011), Cortina et al. (2001), and Bennett and Robinson (2000) to capture undermining, incivility, and deviance, respectively. Due to the limit on the questionnaire length, however, we could not use full scales to capture these interpersonal destructive behaviors. We thus selected two items from Bennett and Robinson (2000), two items from Cortina et al. (2001), and one item each adapted from Duff et al. (2006) and Lam et al. (2011) and then averaged participants' responses to form an overarching 
variable of interpersonal destructive behavior. Sample items are: "He/she put me down or be condescending to me," "He/she acts rudely toward me," and "He/she harms my performance.” (1= strongly disagree, 7 = strongly agree, $\alpha=.98$ ).

Control variables. We considered a number of control variables. First, we controlled for deservingness, because when third parties judge victims of abusive supervision as deserving such treatment, they tend to be less sympathetic to the victims (Deutsch 1990; Feather 2006; Mitchell et al. 2015). We measured deservingness using a three-item, seven-point scale adapted from Heuer et al. (1999) and Feather $(1998 ; \alpha=.94)$. A sample item is "This group member deserves to be treated poorly by the supervisor.” Second, to build our model on and also extend Mitchell et al.’s (2015) model, we also controlled for the interactive term of observed abusive supervision and deservingness. Third, victims who have a poor relationship with observers may report receiving higher levels of destructive behavior from the observers (Spector and Brannick 2011); and given that rivalry does not require an antagonistic relationship, we therefore controlled for victims' reported relationship quality with observers by using Sherony and Green’s (2002) coworker exchange scale (e.g., "How would you describe your relationship with this group member?” 1 = very bad; $5=$ very good; $\alpha=.91$ ). We have also considered gender, as previous studies have shown it to be related to antisocial behaviors (e.g., Aquino et al. 1999, Duffy et al. 2006). The correlation results, however, indicated that gender was not related to interpersonal destructive behavior, and thus we did not include it. It is worth noting that our results remained essentially the same when we removed each of the control variables respectively or all of them together.

\section{Data Analysis}

We conducted a multilevel analysis using a specific hierarchical linear modeling application of Kenny’s (1994) social relations model (SRM; Snijders and Kenny 1999). SRM has been used in recent organizational behavior research examining dyadic relationships within work teams (e.g., Van der Vegt et al. 2006, de Jong et al. 2007). SRM analysis is capable of partitioning variance into different levels, including group, actor, target, and dyad, and thus it distinguishes fixed effects from random effects. The random-effects estimates indicate the percentage of the total variance in an 
actor's schadenfreude and interpersonal destructive behavior toward a target that is attributable to characteristics of the actor, the target, the dyadic relationship, and the group. The fixed-effects estimates indicate the strength of the relationship between the predictor variables and the outcome variables.

We analyzed the data using the MLwiN computer package (Goldstein et al. 1998). To test our hypotheses, we followed a three-step procedure. First, we calculated a null model as the reference for subsequent analyses, which contained no predictor variables. Second, we added the predictor variables to the subsequent SRM models (see Table 2). We used a chi-square difference test to determine whether there was a decrease in log-likelihood between each of the models, and this enabled us to evaluate the statistical significance of any model fit improvements (e.g., de Jong et al. 2007). Third, we conducted Monte Carlo analyses to examine the conditional indirect effect of observed abusive supervision on interpersonal destructive behavior via schadenfreude. We centered the independent variables at their grand means before the analysis (Aiken and West 1991).

\section{STUDY 2: RESULTS AND DISCUSSION}

\section{Descriptive Statistics and Variance Partitioning}

Table 2 presents the descriptive statistics and bivariate correlations for the variables. The analyses of variance partitioning showed that there are $7.23 \%, 66.27 \%, 1.20 \%$, and $25.30 \%$ of variances of schadenfreude at group, actor, target, and dyad levels, respectively, and 7.87\%, $0.41 \%$, $63.42 \%$, and $28.31 \%$ of variances of interpersonal destructive behavior at group, actor, target, and dyad levels, respectively.

Insert Table 2 about here

\section{Hypothesis Testing}

Hypothesis 1 predicted the two-way interactive effect of observed abusive supervision and perceived rivalry on third parties' schadenfreude. In Model 1 of Table 3, we first entered the control variables and the independent variables. In Model 2, we entered the two-way interaction terms of observed abusive supervision and rivalry and observed abusive supervision and group cooperative goals, respectively. As expected, the interaction term of observed abusive supervision and rivalry was 
significantly related to schadenfreude (Model 2 of Table 3; $\beta=.12, p<.01$ ). We tested the simple slopes (Aiken and West 1991) to further confirm the two-way interactive effect of observed abusive supervision and perceived rivalry on schadenfreude. The results indicated that, as predicted, when the third-party observer perceived that he/she had a high level of rivalry relationship with the victim of abusive supervision, the third party felt schadenfreude toward the victim $(\beta=.20 p<.01)$. By contrast, when the observer perceived a low rivalry relationship with the victim, observed abusive supervision was not significantly related to schadenfreude $(\beta=-.04$, n.s.). Thus, Hypothesis 1 was supported. Figure 3 shows this interactive effect on schadenfreude.

Hypothesis 2 predicted a conditional indirect effect of observed abusive supervision on interpersonal destructive behavior through schadenfreude when perceived rivalry is high. As shown in Model 1b of Table 2, schadenfreude was positively related to interpersonal destructive behavior $(\beta$ $=.11, p<.05$ ), providing initial evidence for the mediating effect of schadenfreude. We then performed a Monte Carlo-based simulation (10,000 repetitions) to test the moderated indirect effect. Following Krull and MacKinnon’s (2001) procedure, we drew on the simple slope estimates of the relationship between observed abusive supervision (ranging from high [+1 SD] to low [-1 SD] values) and schadenfreude at low and high values of perceived rivalry, and we also drew on the estimate of the relationship between schadenfreude and the dependent variable. We then used these estimates to examine the conditional indirect link between observed abusive supervision and interpersonal destructive behavior through schadenfreude at low and high values of perceived rivalry. We used Selig and Preacher’s (2008) Monte Carlo method to estimate percentile confidence intervals around the population values of the conditional indirect relations (for similar approaches, see Zhou et al. 2012, Lorinkova et al. 2013). The results of the Monte Carlo-based simulation (10,000 repetitions; see Table 4) indicated that the indirect path from the observed abusive supervision to interpersonal destructive behavior via schadenfreude was significant $(.02$; 95\% CI $[.0013, .0515])$ when perceived rivalry was high. When perceived rivalry was low, the indirect path was not significant. Therefore, Hypothesis 2 was supported.

Hypothesis 3 predicted a three-way interactive effect of observed abusive supervision, 
perceived rivalry, and group cooperative goals on schadenfreude. As shown in Model 4 of Table 3, the three-way interaction was significantly related to schadenfreude $(\beta=-.18, p<.001)$. Simple slope tests (Aiken and West 1991) further confirmed that observed abusive supervision was positively related to schadenfreude only when the level of cooperative goals was low and perceived rivalry was high $(\beta=.45, p<.001)$, supporting Hypothesis 3 . The simple slopes for the other three conditions (i.e., low cooperative goals and low perceived rivalry; high cooperative goals and high perceived rivalry; and high cooperative goals and low perceived rivalry) were not significant $(\beta=-.10, S E=.10 ; \beta=$ $-.15, S E=.11 ; \beta=-.01, S E=.12$; respectively). Figure 4 shows the three-way interactive effect on schadenfreude.

Insert Tables $3 \& 4$ and Figures $3 \& 4$ about here

Hypothesis 4 predicted a conditional indirect effect of observed abusive supervision on interpersonal destructive behavior through schadenfreude when group cooperative goals are low and perceived rivalry is high. The results of the Monte Carlo test (10,000 repetitions) indicated that when cooperative goals were low and perceived rivalry was high, the indirect path was significant (.05; 95\% CI [.0064, .1016]). As shown in Table 4, however, under the other three conditions, the indirect paths were not significant. Therefore, Hypothesis 4 was supported.

In Study 2, we found support for our hypotheses, but this study had two weaknesses. First, we did not consider some important control variables, especially those related to the justice-based approach to third parties' reactions to abusive supervision, such as belief in a just world and moral identity. Moreover, we did not control for the effect of third parties' relationship with the abusive supervisor (e.g., leader-member exchange), which also might influence third parties' reactions to observed abusive supervision. Furthermore, given that contentment may serve as an alternative underlying emotional mechanism of third parties’ malicious reactions to observed abusive supervision (e.g., Mitchell et al. 2015), to demonstrate a unique effect of schadenfreude, it is critical to control for the effect of contentment. Second, because of the restraint on the length of the questionnaire imposed by the study company, we had to select items from scales of undermining, incivility, and deviance and 
took the mean of these items to capture interpersonal destructive behavior. It would have been desirable to measure these three constructs separately and replicate our findings in Study 1 . We therefore conducted Study 3 to address these concerns.

\section{STUDY 3: METHODS}

\section{Sample and Procedures}

We conducted an on-site survey at a large chemical company in China. Participants were employees from different departments (e.g., R\&D, engineer technology, information technology, marketing, and production). We collected data in two waves with a one-month interval, using the same round-robin design that we used in Study 2. At Time 1, we collected data on the control variables, and participants' self-rating of observed abusive supervision, perceived rivalry, group cooperative goals, and schadenfreude. At Time 2, we measured undermining, incivility, and interpersonal deviance using the same peer rating as in Study 2 to reduce common method bias (Podsakoff et al. 2003).

We administered the surveys to 405 employees from 90 work groups, ranging in size from 3 to 10 members. We invited all participants of the 90 work groups to participate in the survey. As a token of appreciation, we provided US\$12 as an incentive to participants who completed both Time 1 and 2 surveys. Participants were briefed before the survey and assured confidentiality. They returned the surveys to the researchers immediately upon completion. After matching the responses from both waves and excluding incomplete dyads, the final sample consisted of 395 employees from 90 work groups, with 1,669 usable dyadic relations. The effective response rate was $98 \%$. Seventy-five percent of the respondents were men, and 94\% had received a college education or above. The mean age of the respondents was 33 years $(S D=6.01)$, and the mean tenure was 8.37 years $(S D=6.48)$.

\section{Measures}

We measured observed abusive supervision ( $\alpha=.87$ ), group cooperative goals ( $\alpha=.91$ ICC $_{1}$ $=.34, \mathrm{ICC}_{2}=.78$, Median $\left.\mathrm{r}_{\mathrm{wg}(\mathrm{j})}=.97\right)$, and schadenfreude $(\alpha=.94)$ using the same measures that we used in Study 2. In Study 3, we used a four-item scale developed by Kilduff (2014) to assess perceived rivalry. Sample items are "I feel rivalry towards him/her" and "I consider him/her to be a 
personal rival” $(1=\text { strongly disagree, } 7=\text { strongly agree; } \alpha=.92)^{1}$. We measured undermining using the same two-item scale from Duffy et al. as in Study 1 (2006; 1 = strongly disagree; 7 = strongly agree; $\alpha=.94)$. One sample item is "Sometimes he/she makes it difficult for me to do my job well." We measured incivility and interpersonal deviance using the same scales as we used in Study 1. To reduce rating fatigue resulted from round-robin rating, however, we chose to include only the three items with the highest factor loadings from the scale of incivility (Cortina et al. 2001; $\alpha=.96$ ) and interpersonal deviance (Bennett and Robinson 2000; $\alpha=.97$ ).

Control variables. First, as we discussed earlier that we need to control justice-based variables, we thus controlled for individual differences, including belief in a just world (Dalbert 1999; $\alpha=.81$ ) and moral identity, as moral identity may affect individuals’ tendency to conduct harming behaviors (e.g., "Being someone who has these characteristics [e.g., caring, kind, friendly] is an important part of who I am”; Aquino and Reed 2002; $\alpha=$.82). Second, as we discussed earlier in Study 2, we controlled for third parties' leader-member exchange relationship with supervisors (LMX, e.g., "How would you characterize your working relationship with your supervisor?” Graen and Uhl-Bien 1995; $\alpha=.86$ ). Third, we controlled for relationship quality between third parties and victims of abusive supervision by using a more direct measure, interpersonal dislike; controlling for this measure may also help us to tease out the effect of interpersonal dislike on schadenfreude. Fourth, we controlled for the main effect of moral exclusion belief, as well as the interactive effect of observed abusive supervision and moral exclusion belief, because we attempted to empirically demonstrate that our model can provide an additional explanation for observers' malicious reactions above and beyond the moral exclusion explanations identified in Mitchell et al.’s (2015) work. Last, similar to Study 1, we controlled for contentment ( $\alpha=$.87). Note that our results remained essentially the same when we removed each of the control variables respectively or all of them together.

\section{STUDY 3: RESULTS AND DISCUSSION}

\section{Descriptive Statistics and Variance Partitioning}

\footnotetext{
1 Note that our Study 2 was conducted before the publication of Kilduff's (2014) paper, and thus we used the three-item scale extended from Kiduff et al.'s (2010) one-item scale in Study 2. The correlation of the scale developed by Kilduff (2014) and the three-item scale used in Study 2 was .94 $4^{* * *}(p<.001)$.
} 
Table 5 presents the descriptive statistics and bivariate correlations for the variables at different levels. The analyses of variance partitioning showed that $8.76 \%, 71.61 \%, 0.3 \%$, and $19.30 \%$ variances of schadenfreude are at group, actor, target, and dyad levels, respectively. For the dependent variables, $45.92 \%$, 1.04\%, 40.78\%, and $12.26 \%$ variances of undermining; $45.49 \%, 0.85 \%, 41.98 \%$, and $11.68 \%$ variances of incivility; and $42.38 \%, 0.06 \%, 46.99 \%$, and $10.56 \%$ variances of interpersonal deviance are at group, actor, target, and dyad levels, respectively.

\section{Hypothesis Tests}

We first tested Hypothesis 1. As shown in Model 2 of Table 6, the interaction term of observed abusive supervision and perceived rivalry was significantly related to schadenfreude $(\beta=.09$, $p<.001$ ). The results of the simple slopes tests (Aiken and West 1991) further confirmed that when the third party perceived that he/she had a high level of rivalry relationship with the victim, the third party felt schadenfreude toward the victim $(\beta=.17, p<.001)$. By contrast, when the third party perceived a low rivalry relationship with the victim, observed abusive supervision was not significantly related to schadenfreude $(\beta=-.02$, n.s.). Thus, Hypothesis 1 was supported. Figure 5 shows the interactive effect on schadenfreude.

Insert Tables $5 \& 6$ and Figure 5 about here

We then tested Hypothesis 2. As shown in Table 7, schadenfreude was positively related to undermining (Model 1; $\beta=.13, p<.001$ ), incivility (Model 3; $\beta=.14, p<.001$ ), and interpersonal deviance (Model 5; $\beta=.09, p<.01$ ), providing initial evidence for the mediating effect of schadenfreude. We then performed a Monte Carlo-based simulation (10,000 repetitions; Selig and Preacher 2008) to confirm the moderated indirect effect. The results of the Monte Carlo-based simulation (see Table 8) indicated that the indirect paths from observed abusive supervision to interpersonal destructive behaviors via schadenfreude were significant when perceived rivalry was high (undermining = .02; 95\% CI [.0085, .0371]; incivility = .03; 95\% CI [.0132, .0359]; interpersonal deviance $=.02 ; 95 \%$ CI $[.0052, .0265])$. When perceived rivalry was low, the indirect paths were not significant. Therefore, Hypothesis 2 was supported. 
As shown in Model 4 of Table 6, the three-way interaction term was significantly related to schadenfreude $(\beta=-.07, p<.01$ ). Simple slope tests (Aiken and West, 1991) further confirmed that observed abusive supervision was positively related to schadenfreude only when the level of cooperative goals was low and perceived rivalry was high $(\beta=.25, p<.001)$. The simple slopes for the other three conditions (i.e., low cooperative goals and low perceived rivalry; high cooperative goals and high perceived rivalry; and high cooperative goals and low perceived rivalry) were not significant $(\beta=-.06, S E=.06 ; \beta=.06, S E=.06 ; \beta=.01, S E=.05$; respectively). Thus, Hypothesis 3 was supported. Figure 6 shows the three-way interactive effect on schadenfreude.

Insert Tables $7 \& 8$ and Figure 6 about here

We then tested Hypothesis 4, the conditional indirect effect of the three-way interactive effect on destructive behaviors through schadenfreude. The results of the Monte Carlo test $(10,000$ repetitions) indicated that when cooperative goals were low and perceived rivalry was high, the indirect paths were significant for all three dependent variables (undermining $=.04$; $95 \%$ CI [.0142, .0597]; incivility $=.04$; 95\% CI [.0180, .0552]; interpersonal deviance $=.03$; 95\% CI [.0094, .0432]). As shown in Table 8, however, under the other three conditions, the indirect paths were not significant. Therefore, Hypothesis 4 was supported.

In Study 3, we replicated the findings of Studies 1 and 2. Our results remained robust even when we included a few more control variables, such as belief in a just world, moral identity, and LMX. Moreover, we demonstrated that our results remained the same after controlling for moral exclusion belief and the interactive term of observed abusive supervision and moral exclusion belief. Furthermore, we showed that after controlling for contentment, an emotion leading to coworkers' unsympathetic reactions to observed abusive supervision, as reported in Mitchell et al.’s study (2015), schadenfreude remained as a robust mechanism underlying the links between observed abusive supervision and interpersonal destructive behaviors.

\section{DISCUSSION}

How do people react to the abusive supervision of their coworkers? Drawing on the theory of 
rivalry (Kilduff et al. 2010), we examined the role of interpersonal rivalry and found evidence that when observers perceive a rivalry relationship with victims of abusive supervision, they experience a feeling of schadenfreude toward their rival victims, which then leads them to socially undermine them, behave rudely toward them, and engage in deviance toward them. Moreover, we identified group cooperative goals as an important contextual factor that regulates these interpersonal dynamics. When group cooperative goals are high, the above two-way interactive effect on schadenfreude is no longer significant. In other words, a high level of cooperative goals tends to inhibit third parties from deriving "evil pleasure" from observing abusive supervision of a rival and to prevent them from further harming the victim. By contrast, only when cooperative goals are low and interpersonal rivalry is high do observers experience schadenfreude toward the victims. This feeling then causes third parties to engage in interpersonal destructive behaviors toward abused victims.

\section{Theoretical Implications and Future Research Directions}

The findings of our study have several theoretical implications. First, departing from previous studies' justice-based perspectives, we proposed and examined the cause of observers' malicious reactions based on theory of rivalry and the associated social comparison perspective. In specific, we proposed and found that rivalry plays a critical role in leading observers to experience evil pleasure when observing their rivals being mistreated by supervisors. We obtained consistent results across three studies by controlling for several justice-related variables, including third parties’ belief in a just world (e.g., Lerner, 1965, 1980), moral identity (Aquino and Reed 2002), dislike of the victims (e.g., Blader et al. 2013), moral exclusion beliefs about the victims, and the interactive effect of observed abusive supervision and moral exclusion beliefs (e.g., Mitchell et al. 2015). This suggests that when third-party observers perceive a rivalry relationship with victims of abusive supervision, their fairness judgment of whether victims deserve it or their sense of being a moral person may recede to the background. Instead, observing the rival's downfall induces a social comparison advantage. Such superiority brings an irresistible feeling of pleasure that may dictate the third parties to further reinforce such superiority and reward the evil pleasure by doing more harm.

Our findings may have implications for broader social and organizational phenomena. For 
example, supervisors' constructive feedback, disciplinary actions, or punishment of rival colleagues may also induce third-party observers' schadenfreude, as the observers may feel delight generated by the social comparison advantages resulted from the above supervisors' actions toward the rival colleague. In our view, these actions, unlike abusive supervision, would not completely veto or humiliate the targets. Rather, they may send ambiguous signals to third-party observers and thus may not trigger rival observers' schadenfreude toward the targets. Essentially, schadenfreude means joy at someone’s misfortune or downfall (Leach et al., 2003). Constructive feedback, disciplinary actions, or punishment may not necessarily be construed as actions causing the targets' misfortunes or downfall. By contrast, abusive supervision is fundamentally about supervisors' sustained display of hostile verbal and non-verbal behaviors (Tepper, 2000). In terms of intensity, abusive supervision is more intense and less ambiguous than other behaviors that could be regarded as misfortunes or downfall. Future research could further examine whether other forms of supervisory behaviors may have similar effects on third-party observers' reactions.

Second, our findings shed light on the role of schadenfreude in third parties' reactions to victims. Mitchell et al.'s (2015) study revealed that when victims are believed to deserve unfair treatment, third parties feel contentment, a peaceful and serene emotion when they observed the abusive supervision of the victims. It is possible that third parties feel peaceful and serene because justice has served itself, as those who deserve to be punished are indeed mistreated by supervisors. Our study, however, suggests that in a rivalry relationship, observing abusive supervision of a rival makes third parties experience more active and aroused emotion, making them "sing and dance" over their rival's wounds. To demonstrate the superior effect of schadenfreude to contentment in our model, we performed additional analyses in both Study 1 and Study 3 to examine whether perceived rivalry also moderates the relationship between observed abusive supervision and contentment. The interaction term of observed abusive supervision and perceived rivalry was, however, not significantly related to contentment in either study. And, after controlling for contentment, the results still supported our model.

Third, our findings suggest that although abusive supervision of certain targets can breed 
hostility among rival coworkers, this can be substantially curbed when work groups develop highly cooperative goals. This finding provides not only evidence for the importance of contextual factors in regulating the destructive effect of rivalry among team members but also a practical solution to suppress coworkers' opportunistic harming toward their rival members if abusive supervision is inevitable. Given that rivalry has both a beneficial force in motivating individuals to improve their effort-based performance (Kilduff et al. 2010) and a destructive effect on unethical behaviors (Kilduff et al. 2016), future research could examine whether group norms can suppress the destructive effect of rivalry while facilitating its motivational function.

Finally, we found that schadenfreude was strongly associated with interpersonal destructive behaviors. This finding complements our understanding of the emotion-behavior link regarding schadenfreude. Research on emotions has suggested that emotions elicited from a particular situation promote behaviors that satisfy the demands of the precipitating situation (Frijda 1988, Weiss and Cropanzano 1996), and recent neuropsychological research also points to the possible association between schadenfreude and harming intentions (e.g., Cikara et al. 2011). Our study provides evidence supporting this emotion-behavior link by suggesting that schadenfreude induced by observing abusive supervision of victims leads to observers' interpersonal destructive behaviors toward the victims. A post hoc analysis showed that cooperative goals could not attenuate the positive link between schadenfreude and interpersonal destructive behaviors, suggesting that despite its passive and opportunistic nature, schadenfreude has strong behavioral implications. Related to this point, it is also possible that schadenfreude may fuel competition-related motivational states (e.g., motivation to win), which in turn could translate into further harming behavior toward rival victims of abusive supervision to reinforce the social comparison advantages. Future research could explore the potentially intervening link between schadenfreude and the harming behavior that follows.

\section{Strengths and Limitations}

The present investigation has two key strengths. One is its constructive replication of our core predictions across one experimental study and two independent field studies. Such replication allowed us to counterbalance potential weaknesses of each study. The present research thus provides strong 
evidence to support our theorization of observers' malicious reactions toward victims of abusive supervision, demonstrates the internal and external validity of our results, and extends the generalizability of our model in different industries. The other strength is its application of social relations modeling to study the observer effect of abusive supervision. As Skarlicki and Kulik (2004, p. 216) pointed out, "studying third parties in real world and naturalistic settings . . . can be more difficult," because it is hard for researchers to identify the third parties associated with a particular organizational incident. Thus, past studies have relied on the critical incident technique (e.g., Mitchell et al. 2015) to study the third-party effect by instructing respondents to recall the observations of the abusive supervision of a specific coworker. This technique has its own limitations, because it uses a same-source design that may lead to common method variance bias. Moreover, the critical incident technique is applied mainly to study individual-level variables. The model proposed in our study focuses on dyadic interactions among group members and thus involves relational factors (i.e., rivalry) and group factors (i.e., group cooperative goals). Social relations modeling (SRM), a specific multilevel analysis, allows us to model dyadic level, individual level, and group level variables all together to examine our hypotheses.

That said, the current research is not without limitations. First, our field studies (Studies 2 and 3) face a key problem of field surveys: the potential threat of reverse causality. Although our results of Study 2 and Study 3 are based on a multi-source and time-lagged design, we cannot draw firm conclusions about causality. Nonetheless, it is untenable to argue for a reverse relationship, given the nature of schadenfreude. By definition, schadenfreude refers to people’s joy at others' misfortunes (Smith et al. 1996, Leach et al. 2003). Without others’ misfortunes in the first place, schadenfreude comes from nowhere. Therefore, a reverse causality is less likely than what we proposed and found in the current research. Second, the mediator in our model is schadenfreude, which is a state variable reflecting the feeling experienced when observing coworkers being abused by supervisors. Relying on recalled memories to assess such emotion is less valid and reliable than using the experience sampling method (Wheeler and Reis 1991). Future research would benefit from using this method to replicate and extend our findings. 
Third, the cultural context of China where we collected our data may influence our results. A key consensus in cross-cultural research is that individuals from nations with a higher level of collectivistic culture tend to cooperate more and compete less within workgroups (e.g., Wagner, 1995, Eby and Dobbins 1997, Chen and Li 2005; Keller and Loewenstein 2011). It is possible that individuals are less likely to develop rivalry relationships within workgroups in China, which has a more collectivistic culture than other countries, such as the United States. Thus, our results can be seen as the outcomes of a conservative test, in that we would expect stronger moderating effects of rivalry for individuals from more individualistic cultures. In addition, high power distance culture in China may influence how employees assess and react to abusive supervision. Lin, Wang, and Chen (2013) found that the negative effect of abusive supervision on employees' well-being is mitigated by a higher power distance orientation. Similarly, Vogel et al. (2015) showed that employees from Anglo culture reacted to abusive supervision more negatively than employees from Confucian culture and that this national difference could be explained by power distance values. Lian, Ferris, and Brown (2012) demonstrated that individuals with a higher power distance orientation tend to view abusive supervision as less interpersonally unfair. They also found that individuals high on power distance orientation tend to see abusive supervision as rewarding to the supervisors and tend to follow their abusive supervision to mistreat coworkers. A recent meta-analytical study (Zhang and Liao 2015) shows that the positive effects of abusive supervision on deviance behavior is stronger (rather than weaker) in countries with a lower power distance culture. Hence, although the above previous studies focused on victims' reactions to supervisors, it would be desirable for future research to examine whether power distance values play a similar role in third parties' reactions to workplace mistreatment.

\section{Practical Implications}

Our findings offer several practical implications. First, past studies have revealed that abusive supervision exerts a destructive force on the targeted employees; our study showed that abusive supervision also can deteriorate coworker relationships by activating some observers' evil pleasure and interpersonal deviance toward the targets of abusive supervision. Organizations, therefore, should 
be aware of the profound effect of abusive supervision on coworker relationships within work groups and take actions to reduce abusive supervision at work.

Second, organizations are fertile ground for cultivating rivalry among employees. Managers should be alert to the possible detrimental effects of interpersonal rivalry, as identified in our research. Although rivalry has been found to promote greater work effort (e.g., Kilduff et al. 2010), it also has been associated with irrational decision-making (e.g., Ku et al. 2005) and unethical behaviors (Kilduff et al. 2016). Our findings demonstrate the detrimental role of rivalry in spreading the destructive effects of an abusive supervisor. Therefore, a big challenge facing organizations is how to benefit from the positive effects of competition at work while minimizing the negative side. Our results suggest that one way to counteract the detrimental effects of interpersonal rivalry is to establish and reinforce group cooperative goals. We found that observers' malicious reactions toward the abusive supervision of rival coworkers can be mitigated if the group has highly cooperative goals. This may provide a way forward for organizations to continue to reap the benefits of competition while reducing mistreatment among coworkers. Managers may cultivate a harmonious work climate, implement interdependent goals among team members, instill the concept of a shared identity, and enhance members’ identification with and attachment to the group (Shamir et al. 1998).

\section{References}

Aiken LS, West SG (1991) Multiple regression: Testing and interpreting interactions (Sage, Newbury Park).

Aquino K, Lewis MU, Bradfield M (1999) Justice constructs, negative affectivity, and employee deviance: A proposed model and empirical test. J. Organ. Behav. 20: 1073-1091.

Aquino K, Reed A (2002) The self-importance of moral identity. J. Personality Soc. Psych. 83: 1423-1440. Bandura A (1977) Social learning theory (Prentice-Hall, Englewood Cliffs).

Baumeister R (1991) The self against itself: Escape or defeat? In RC Curtis (Ed.) The relational self: Theoretical convergences in psychoanalysis and social psychology (The Guilford Press, New York): 238-256.

Bennett RJ, Robinson SL (2000) Development of a measure of workplace deviance. J.Appl. Psych., 85: 349-360.

Bettenhausen K, Murnighan JK (1991) Developing and challenging a group norm: Interpersonal cooperationa nd structural competition. Admin. Sci. Quart. 36: 20-35.

Blader SL, Wiesenfeld BM, Fortin M, Wheeler-Smith SL (2013) Fairness lies in the heart of the beholder: How the social emotions of third parties influence reactions to injustice. Organ. Behav. Human Decision Processes 121: 62-80.

Brislin RW, Lonner WJ, Thorndike RM (1973) Cross-cultural research methods (John Wiley, New York).

Brown JD, Dutton KA (1995) The thrill of victory, the complexity of defeat: Self-esteem and people's emotional reactions to success and failure. J. Personality Soc. Psych. 68: 712-722.

Brown SP, Cron WL, Slocum JW (1998) Effects of trait competitiveness and perceived intraorganizational competition on salesperson goal setting and performance. J. Marketing, 62: 88-98.

Burnett S, Bird G, Moll J, Frith C, Blakemore SJ (2009) Development during adolescence of the neural 
processing of social emotion. J. Cognitive Neuroscience, 21: 1736-1750.

Buunk AP, Gibbons FX (2007) Social comparison: The end of a theory and the emergence of a field. Organ. Behav. Human Decision Processes. 102: 3-21.

Buunk AP, Zurriaga R, Peiro JM, Nauta A, Gosalvez I (2005) Social comparisons at work as related to a cooperative social climate and to individual differences in social comparision orientation. Appl. Psych. 54: 61-80.

Chen XP, Li S (2005) Cross-national differences in cooperative decision-making in mixed-motive business contexts: The mediating effect of vertical and horizontal individualism. J. Intenat. Bus. Stud. 36: 622-636.

Cikara M, Botvinick MM, Fiske ST (2011) Us versus them: Social identity shapes neural responses to intergroup competition and harm. Psych. Sci. 22: 306-313.

Cikara M, Fiske ST (2011) Bounded empathy: Neural responses to outgroup targets' (mis)fortunes. $J$. Cognitive Neuroscience. 23: 3791-3803.

Cortina LM, Magley VJ, Williams JH, Langhout RD (2001) Incivility in the workplace: incidence and impact. J. Occupational Health Psych. 6: 64-80.

Dalbert C (1999) The world is more just for me than generally. Soc. Justice Res. 12: 79-98.

de Jong SB, Van der Vegt GS, Molleman E (2007) The relationships among asymmetry in task dependence, perceived helping behavior, and trust. J. Appl. Psych. 92: 1625-1637.

Deutsch M (1949) A theory of cooperation and competition. Human Relations. 2: 129-152.

Deutsch M (1990) Psychologicla roots of moral exclusion. J. Soc. Issues. 46: 21-25.

Duffy MK, Ganster DC, Shaw JD, Johnson JL, Pagon M (2006) The social context of undermining behavior at work. Organ. Beh. and Human Decision Processes. 101: 105-126.

Eby LT, Dobbins GH (1997) Collectivistic orientation in teams: An individual and group-level analysis. $J$. Organ. Behav. 18: 275-295.

Edward JR, Lambert LS (2007) Methods for integrating moderation and mediation: A general analytical framework using moderated path analysis. Psycho. Methods. 12: 1-22.

Feather NT (1998) Judging deservingness and affect in relationj to another's employement or unemployment: a test of a justice model. Eur. J. Soc. Psych. 28: 361-381.

Feather NT (2006) Deservingness and emotions: Applying the structural model of deservingness to the analysis of affective reactions to outcomes. Eur. Rev. Soc. Psych. 17: 38-73.

Festinger L (1954) A theory of social comparison processes. Human Relations. 7: 117-140.

Folger R (2001). Fairness as deonance. In S. W. gilliland, D. D. Steiner, \& D. P. Skarlicki (Eds.), Research in social issues in management (Information Age Publishers, New York): 3-33.

Frijda NH (1988) The laws of emotion. Amer. Psychologist, 43: 349-358.

Furnham A (2003) Belief in a just world: research progress over the past decade. Personality and Individual Differences. 34: 795-817.

Goldstein H, Rasbash J, Plewis I, Draper D, Browne W, Yang M, ... Healy M (1998) A user's guide to MLwiN [Computer software and manual] (University of London, London).

Graen GB, Uhl-Bien M (1995) Relationship-based approach to leadership: Development of leader-member exchange (LMX) theory of leadership over 25 years: Applying a multi-level multi-domain perspective. Leadership Quart. 6: 219-247.

Hareli S, Parkinson B (2008) What's social about social emotions? J. for the Theory of Soc. Behav. 38: 131-156.

Hatfield E, Walster EH, Walster GW, Berscheid E (1978) Equity: Theory and research (Allyn \& Bacon, Boston).

Hayes AF (2013) Introduction to mediation, moderation, and conditional process analysis: A regression-based approach (Guilford Press, New York).

Heuer L, Blumenthal E, Douglas A, Weinblatt T (1999) A deservingness approach to respect as a relationally based fairness judgment. Personality Soc. Psych. B. 25: 1279-1292.

James LR (1982) Aggregation bias in estimates of perceptual agreement. J. Appl. Psych. 67: 219-229.

James LR, Demaree RG, Wolf G (1984) Estimating within-group interrater reliability with and without response bias. J. Appl. Psych. 69: 85-98.

James S, Kavanagh PS, Jonason PK, Chonody JM, Scrutton HE (2014) The dark triad, schadenfreude, and sensational interests: Dark personalities, dark emotions, and dark behaviors. Personality and Individual Differences. 68: 211-216.

Johnson DW, Johnson RT (1989) Cooperation and competition: Theory and research (Interaction Books, Edina). 
Jones D (2013) The glot factor. Nature. 500: 147.

Keller J, Loewenstein J (2011) The cultural category of cooperation: A cultural consensus model analysis for China and the United States. Organ. Sci. 22: 299-319.

Kenny DA (1994) Interpersonal perception: A social relations analysis (Guilford Press, New York).

Kiewitz C, Restubog SD, Shoss MK, Garcia PRJM, Tang R (2016) Suffering in silence: Investigating the role of fear in the relationship between abusive supervision and defensive silence. J. Appl. Psych.101: 731-742.

Kilduff GJ (2014) Driven to win: Rivalry, motivation, and performance. Soc. Psych. Personality Sci., 5: 944-952.

Kilduff GJ, Elfenbein HA, Staw BM (2010) The psychology or rivalry: A relationally dependent analysis of competition. Acad. Management J. 53: 943-969.

Kilduff GJ, Galinsky AD (2017) The spark that ignites: Mere exposure to rivals increases Machiavellianism and unethical behavior. J. Experimental Soc. Psych. 69: 156-162.

Kilduff GJ, Galinsky AD, Gallo E, Reade JJ (2016) Whatever it takes to win: Rivalry increases unethical behavior. Acad. Management $J$.

Kim E, Glomb TM (2014) Victimization of high performers: The roles of envy and work group identification. J. Appl. Psych. 99: 619-634.

Kohn A (1992) No context: The case against competition. New York: Houghton mifflin.

Krull JL, MacKinnon DP (2001) Multilevel modeling of individual and group level mediated effects. Multivariate Behav. Res. 36: 249-277.

Ku G, Malhotra D, Murnighan JK (2005) Towards a competitive arousal model of decision-making: A study of auction fever in live and Internet auctions. Organ. Behav. Human Decision Processes. 96: 89-103.

Lam CK, Van der Vegt GS, Walter F, Huang X (2011) Harming high performers: A social comparison perspective on interpersonal harming in work teams. J. Appl. Psych. 96: 588-601.

Leach CW, Spears R, Branscombe NR, Doosje B (2003) Malicious pleasure: Schadenfreude at the suffering of another group. J. Personality Soc. Psych. 84: 932-943.

Lerner M (1965) Evaluation of performance as a function of performer's reward and attractiveness. $J$. Personality Soc. Psych. 1: 355-360.

Lerner M (1980) The belief in a just world: a fundamental delusion. New York: Plenum.

Lian H, Ferris DL, Brown DJ (2012) Does power distance exacerbate or mitigate the effects of abusive supervision? It depends on the outcome. J. Appl. Psych. 97: 107-123.

Lin W, Wang L, Chen S (2013) Abusive supervision and employee well-being: The moderating effect of power distance orientation. Appl. Psych: An Internat. Rev. 62: 308-329.

Lind EA, Kray L, Thompson L (1998) The social construction of injustice: Fairness judgments in response to own and others' unfair treatment by authorities. Organ. Behav. Human Decision Processes. 75 : $1-22$.

Locke KD (2007) Personalized and generalized comparisons: Causes and consequences of variations in the focus of social comparison. Personality Soc. Psych. Bulletin. 33: 213-225.

Lorinkova NM, Pearsall MJ, Sims HP (2013) Examining the differential longitudinal performance of directive versus empowering leadership in teams. Acad. Management J. 56: 573-596.

Mackey JD, Frieder RE, Brees JR, Martinko MJ. (2017) Abusive supervision: A meta-analysis and empirical review. J. Management. 43: 1940-1965.

Malhotra D, Ku G, Murnighan JK (2008) When winning is everything. Harvard Business Rev. 86: 78-86.

Menon T, Blount S (2003) The messenger bias: A relational model of knowledge valuation. Res. Organ. Behav. 25: 137-186.

Menon T, Thompson L, Choi HS (2006) Tainted knowledge vs. tempting knowledge: People avoid knowledge from internal rivals and seek knowledge from external rivals. Management Sci. 52: $1129-1144$.

Mitchell MS, Ambrose ML (2007) Abusive supervision and workplace deviance and the moderating effects of negative reciprocity beliefs. J. Appl. Psych. 92: 1159-1168.

Mitchell MS, Vogel RM, Folger R (2015) Third parties' reactions to the abusive supervision of coworkers. J. Appl. Psych. 100: 1040-1055.

Nandkeolyar, A. K., Shaffer, J. A., Li, A., Ekkirala, S., \& Bagger, J. (2014). Surviving an abusive supervisor: The joint roles of conscientiousness and coping strategies. J. Appl. Psych, 99, 138-150.

O'Reilly J, Aquino K (2011) A model of third parties' morally motivated responses to mistreatment in organizations. Acad. Management Rev. 36: 526-543. 
Opotow S (1990) Moral exclusion and injustice: An introduction. J. Soc. Issues, 46: 1-20.

Peng AC, Schaubroeck JM, Li Y (2014) Social exchange implications of own and coworkers' experiences of supervisory abuse. Acad. Management J. 57: 1385-1405.

Podsakoff PM, MacKenzie SB, Lee JY, Podsakoff NP (2003) Common method biases in behavioral research: A critical review of the literature and recommended remedies. J. Appl. Psych. 88: 879-903.

Preacher KJ, Rucker DD, Hayes AF (2007) Addressing moderated mediation hypothesis: Theory, methods, and prescriptions. Multivariate Behav. Res. 42: 185-227.

Sedikides C, Strube MJ (1997) Self evaluatioin: To thine own self be good, to thine own self be sure, to thine own self be true, and to thine own self be better. In MP Zanna (Ed), Advances in experimental social psychology (Academic Press: San Diego).

Selig JP, Preacher KJ (2008) Monte Carlo method for assessing mediation: An interactive tool for creating confidence intervals for indirect effects [Computer software]. Retrieved from http://www.quantpsy.org.

Shamir B, Zakay E, Breinin E, Popper M (1998) Correlates of charismatic leader behavior in military units: Subordinates' attitudes, unit characteristics, and superiors' appraisals of leader performance. Acad. Management J. 41: 387-409.

Sherony KM, Green SG (2002) Coworker exchange: Relationships between coworkers, leader-member exchange, and work attitudes. J. Appl. Psych. 87: 542-548.

Shrout PE, Bolger N (2002) Mediation in experimental and nonexperimental studies: New procedures and recommendations. Psycho. Methods. 7: 422-445.

Singer T, Seymour B, O'Doherty JP, Stephan KE, Dolan RJ, Frith CD (2006)Empathic neural responses are modulated by the perceived fairness of others. Nature. 439: 466-469.

Skarlicki DP, Kulik CT (2004) Third-party reactions to employee (mis)treatment: A justice perspective. Res. in Organ. Behav. 26: 183-229.

Smith RH (2000) Assimilative and contrastive emotional reactions to upward and downward social comparisons. Suls J, Wheeler L, eds. Handbook of social comparison: Theory and research (Kluwer Academic/Plenum Publishers, New York), 173-200.

Smith RH (2013) The joy of pain: Schadenfreude and the dark side of human nature (Oxford University Press, New York).

Smith R, Turner T, Garonzik R, Leach C, Urch-Durskat C, Weston C (1996) Envy and schadenfreude. Soc. Personality Psych. Compass, 3: 5430-546.

Snijders TAB, Kenny DA (1999). The social relations model for family data: A multilevel approach. Personal Relationships, 6: 471-486.

Spears R, Leach CW (2004) Intergroup schadenfreude: Conditions and consequences. In L. Z. Tiedens \& C. W. Leach (Eds.), The social life of emotions (Cambridge University Press, New York): 336-355.

Spector PE, Brannick MT (2011) Methodological urban legends: The misuse of statistical control variables. Organ. Res. Methods. 14: 287-305.

Takahashi H, Kato M, Matsuura M, Mobbs D, Suhara T, Okubo Y (2009) When your gain is my pain and your pain is my gain: Neural correlates of envy and schadenfreude. Science. 323: 937-939.

Tauer JM, Harackiewicz JM (2004) The effects of cooperation and competition on intrinsic motivation and performance. J. Personality Soc. Psych. 86: 849-861.

Tepper BJ (2000) Consequences of abusive supervision. Acad. Management J. 43: 178-190.

Tesser A (1988) Toward a self-evaluation maintenance model of social behavior. In L. Berkowitz (Ed.), Advances in experimental social psychology (Academic Press, New York): vol. 21, 181-227.

Tesser A, Millar M, Moore J (1988) Some affective consequences of social comparison and reflection processes: The pain and pleasure of being close. J. Personality Soc. Psych. 54: 49-61.

Tjosvold D, Yu ZY, Hui C (2004) Team learning from mistakes: The contribution of cooperative goals and problem-solving. J. Management Stu. 41: 1223-1245.

Tully S (2006) The (second) worst deal ever. CNNMoney.com. http://money.cnn.com/magazines/fortune/fortune_archive/2006/10/16/8390284/index. htm. October 5.

Van der Vegt GS, Bunderson JS, Oosterhof A (2006) Expertness diversity and interpersonal helping in teams: Why those who need the most help end up getting the least. Acad. Management J. 49: 877-893.

van Dijk WW, Ouwerkerk JW, Smith RH, Cikara M (2015) The role of self-evaluation and envy in schadenfreude. Eur. Rev. Soc. Psych. 26: 247-282. 
Vogel RM, Mitchell M, Tepper BJ, Restubog SLD, Hu C, Hua W, Huang JC (2015) A cross-cultural examination of subordinates' perceptions of and reactions to abusive supervision. J. Organ. Behav. 36: 720-745.

Wagner JA (1995) Studies of individualism-collectivism. Effects on cooperation in groups. Acad. Management J. 38: 152-72.

Warner RM, Kenny DA, Stoto M (1979) A new round robin analysis of variance for social interaction data. J. Personality Soc. Psych. 37: 1742-1757.

Wee EXM, Liao H, Liu D, Liu J (2017). Moving from abuse to reconciliation: A power-dependency perspective on when and how a follower can break the spiral of abuse. Acad. Management J. 60: 2352-2380.

Weiss HM, Cropanzano R (1996) Affective events theory: A theoretical discussion of the structure, causes and consequences of affective experiences at work. Res. Organ. Behav. 18: 1-74.

Westaby JD, Pfaff DL, Redding N (2014) Psychology and social networks: A dynamic network theory perspective. American Psychologist. 69: 269-284.

Wheeler L, Reis HT (1991) Self-recording of everyday life events: origins, types and uses. J. Personality, 59: 339-354.

Wills TA (1981) Downward comparison principles in social psychology. Psych. Bulletin, 90: 245-271.

Yam KC, Fehr R, Keng-Highberger FT, Klotz A, Reynolds S. (2016) Out of control: A self-control

Zhang Y, Liao Z (2015) Consequences of abusive supervision: A meta-analytic review. Asia Pacific J. Management 32: 959-987.

Zhou L, Wang M, Chen G, Shi J (2012) Supervisors' upward exchange relationships and subordinate outcomes: Testing the multilevel mediation role of empowerment. J. Appl. Psych. 97: 668-680. 
Table 1. Means, Standard Deviations, and Correlations among the Variables (Study 1)

\begin{tabular}{|c|c|c|c|c|c|c|c|c|c|c|c|c|}
\hline & Variables & M & S.D. & 1 & 2 & 3 & 4 & 5 & 6 & 7 & 8 & 9 \\
\hline 1 & BJW & 3.31 & .64 & - & & & & & & & & \\
\hline 2 & Contentment & 2.92 & 1.47 & -.07 & -- & & & & & & & \\
\hline 3 & Fear & 3.49 & 1.48 & -.08 & $-.22^{* *}$ & -- & & & & & & \\
\hline 4 & Observed abusive supervision & .51 & .50 & -.11 & $-.33^{* * *}$ & $.41^{* * *}$ & -- & & & & & \\
\hline 5 & Rivalry & .50 & .50 & -.05 & .03 & -.11 & .03 & -- & & & & \\
\hline 6 & Schadenfreude & 2.23 & 1.05 & .02 & $.26^{* * *}$ & -.01 & -.01 & .15 & -- & & & \\
\hline 7 & Undermining & 2.44 & 1.14 & $-.19^{*}$ & .05 & .09 & $.16^{*}$ & $.35^{* * *}$ & $.39^{* * *}$ & -- & & \\
\hline 8 & Incivility & 2.32 & .73 & -.11 & .06 & .09 & $.18^{*}$ & .04 & $.36^{* * *}$ & $.59^{* * *}$ & -- & \\
\hline 9 & Interpersonal deviance & 1.52 & .63 & -.13 & .04 & .02 & .05 & $.27^{* * *}$ & $.27^{* * *}$ & $.55^{* * *}$ & $.62^{* * *}$ & -- \\
\hline
\end{tabular}

Note. N = 156; For "Observed abusive supervision,” 1 = high observed abusive supervision condition, and 0 = low observed abusive supervision condition; for "Rivalry," $1=$ high rivalry condition, and $0=$ low rivalry condition.

${ }^{a}$ BJW indicates belief in a just world belief; * $p<.05, * * p<.01, * * * p<.001$. 
Table 2 Means, Standard Deviations, and Correlations among Variables (Study 2)

\begin{tabular}{|c|c|c|c|c|c|c|c|c|c|c|}
\hline & & Mean & S.D. & 1 & 2 & 3 & 4 & 5 & 6 & 7 \\
\hline \multicolumn{11}{|c|}{ Dyadic level variables } \\
\hline 1 & Deservingness & 2.18 & .35 & -- & -.05 & $.47^{* * *}$ & $.21^{* * *}$ & $.47^{* * *}$ & -.06 & -- \\
\hline 2 & Relation quality & 3.32 & .69 & -.01 & -- & -.06 & .02 & -.10 & -.08 & - \\
\hline 3 & Observed AS & 2.15 & .08 & $.50^{* * *}$ & -.05 & -- & $.12^{*}$ & $.35^{* * *}$ & -.06 & -- \\
\hline 4 & Perceived Rivalry & 2.68 & .35 & $.27^{* *}$ & -.03 & .11 & -- & $.15^{* *}$ & -.08 & - \\
\hline 5 & Schadenfreude & 1.82 & 1.12 & $.53^{* * *}$ & -.10 & $.42^{* * *}$ & $.21^{*}$ & -- & .06 & -- \\
\hline 6 & Interpersonal destructive behavior & 3.01 & 1.44 & -.13 & -.11 & -.08 & -.11 & .04 & -- & -- \\
\hline \multicolumn{11}{|c|}{ Individual level variable } \\
\hline 7 & Group cooperative goals & 4.44 & .42 & -.13 & $.24^{* *}$ & $-.34^{* * *}$ & .07 & $-.26^{*}$ & -.16 & - \\
\hline
\end{tabular}

Note. $\mathrm{N}=376$ dyads from 120 employees. Correlations at dyadic level appear above the diagonal; correlations at individual level appear below the diagonal (dyadic level variables were aggregated to individual level);

Group cooperative goals were reported at individual level; all the other variables were reported at dyadic level;

${ }^{\mathrm{a}} \mathrm{AS}$ indicates abusive supervision; ${ }^{*} p<.05,{ }^{* *} p<.01,{ }^{* * *} p<.001$. 
Table 3 Results of Social Relation Model Analyses (Study 2)

\begin{tabular}{|c|c|c|c|c|c|c|c|c|c|c|c|c|c|c|c|c|c|}
\hline & \multirow[b]{3}{*}{ Steps and Variables } & \multicolumn{8}{|c|}{ Schadenfreude } & \multicolumn{8}{|c|}{ Interpersonal destructive behavior } \\
\hline & & \multicolumn{2}{|c|}{ Model 1} & \multicolumn{2}{|c|}{ Model 2} & \multicolumn{2}{|c|}{ Model 3} & \multicolumn{2}{|c|}{ Model 4} & \multicolumn{2}{|c|}{ Model 1a } & \multicolumn{2}{|c|}{ Model 1b } & \multicolumn{2}{|c|}{ Model 1c } & \multicolumn{2}{|c|}{ Model 1d } \\
\hline & & $\boldsymbol{\beta}$ & SE & $\boldsymbol{B}$ & SE & $\boldsymbol{\beta}$ & SE & $\boldsymbol{\beta}$ & SE & $\beta$ & SE & $\beta$ & SE & $\beta$ & SE & $\beta$ & SE \\
\hline \multicolumn{18}{|c|}{ Control Variables (dyadic level) } \\
\hline 1 & Deservingness & $.20^{* * *}$ & .04 & $.21^{* * *}$ & .04 & $.21^{* * *}$ & .04 & $.21^{* * *}$ & .04 & -.01 & .05 & -.04 & .05 & -.01 & .05 & -.04 & .05 \\
\hline 2 & Relationship quality & -.04 & .05 & -.04 & .05 & -.03 & .05 & -.04 & .05 & $-.21^{*}$ & .09 & -.02 & .09 & $-.21^{*}$ & .09 & $-.21^{*}$ & .09 \\
\hline \multicolumn{18}{|c|}{ Independent Variables(dyadic level) } \\
\hline $\begin{array}{l}3 \\
4\end{array}$ & $\begin{array}{l}\text { (AS) } \\
\text { Perceived rivalry (PR) }\end{array}$ & $\begin{array}{l}.06 \\
-.02\end{array}$ & $\begin{array}{l}.06 \\
.05\end{array}$ & $\begin{array}{l}.03 \\
.01\end{array}$ & $\begin{array}{l}.06 \\
.05\end{array}$ & $\begin{array}{r}.04 \\
-.00\end{array}$ & $\begin{array}{l}.06 \\
.05\end{array}$ & $\begin{array}{r}.04 \\
-.04\end{array}$ & $\begin{array}{l}.06 \\
.05\end{array}$ & $\begin{array}{l}-.03 \\
-.01\end{array}$ & $\begin{array}{l}.06 \\
.06\end{array}$ & $\begin{array}{l}-.03 \\
-.04\end{array}$ & $\begin{array}{l}.06 \\
.06\end{array}$ & $\begin{array}{l}-.02 \\
-.02\end{array}$ & $\begin{array}{l}.06 \\
.06\end{array}$ & $\begin{array}{l}-.03 \\
-.05\end{array}$ & $\begin{array}{l}.06 \\
.06\end{array}$ \\
\hline \multicolumn{18}{|c|}{ Independent Variable(group level) } \\
\hline \multirow[t]{2}{*}{5} & Cooperative goal (CG) & $-.22^{*}$ & .09 & $-.23^{*}$ & .09 & $-.24^{*}$ & .09 & $-.24^{*}$ & .09 & -.13 & .13 & -.11 & .13 & -.13 & .14 & -.10 & .14 \\
\hline & Two-way Interaction & & & & & & & & & & & & & & & & \\
\hline 6 & AS*deservingness (control) & -.01 & .04 & -.01 & .04 & -.01 & .04 & -.04 & .04 & .01 & .05 & .00 & .05 & .01 & .05 & -.00 & .05 \\
\hline 7 & $\mathrm{AS} * \mathrm{PR}$ & & & $.12^{* *}$ & .04 & $.13^{* *}$ & .04 & $.10^{*}$ & .04 & -.01 & .05 & -.04 & .06 & -.02 & .05 & -.05 & .06 \\
\hline 8 & $\mathrm{AS} * \mathrm{CG}$ & & & $-.14^{*}$ & .06 & $-.14^{*}$ & .06 & $-.13^{*}$ & .06 & .07 & .07 & .08 & .07 & .08 & .07 & .08 & .07 \\
\hline \multirow[t]{2}{*}{9} & $\mathrm{PR} * \mathrm{CG}$ & & & & & .08 & .04 & .01 & .05 & & & & & -.03 & .06 & -.03 & .06 \\
\hline & Three-way Interaction & & & & & & & & & & & & & & & & \\
\hline \multirow[t]{2}{*}{10} & $\mathrm{AS} * \mathrm{PR} * \mathrm{CG}$ & & & & & & & $-.18^{* * *}$ & .05 & & & & & -.04 & .06 & -.03 & .06 \\
\hline & Mediator & & & & & & & & & & & & & & & & \\
\hline \multirow[t]{3}{*}{11} & Schadenfreude & & & & & & & & & & & $.11^{*}$ & .05 & & & $.11^{*}$ & .05 \\
\hline & $\chi^{2}$ & & 805.45 & & 94.47 & & 794.47 & & 80.66 & & 42.37 & & 38.32 & & 42.14 & & 38.16 \\
\hline & $\Delta \chi^{2}(\mathrm{df})$ & & & 10.9 & $*^{* *}(2)$ & & $0(1)$ & 13.81 & **** (1) & & & & $55^{*}(1)$ & & $3(1)$ & 3.98 & \\
\hline
\end{tabular}




\section{Table 4 Results of the Moderated Path Analysis ${ }^{\mathrm{a}}$ (Study 2)}

\begin{tabular}{|c|c|c|c|c|c|}
\hline & \multirow{3}{*}{ Conditions $^{\mathrm{b}}$} & \multicolumn{2}{|c|}{ Observed abusive supervision $\rightarrow$} & Schadenfreude & $\rightarrow$ Interpersonal destructive behavior \\
\hline & & $\mathrm{Pxm}^{\mathrm{c}}$ & $\mathrm{Pmy}^{\mathrm{c}}$ & & direct effect \\
\hline & & Estimate (S.E) & Estimate (S.E) & Pxm X Pmy & 95\% confidence interval ${ }^{\mathrm{d}}$ \\
\hline \multirow{2}{*}{ Two-way } & High PR & $.20^{* *}(.07)$ & \multirow{2}{*}{$.11^{*}(.05)$} & $.02^{*}$ & $(.0013, .0515)$ \\
\hline & Low PR & $-.04(.07)$ & & -.01 & $(-.0292, .0082)$ \\
\hline \multirow{4}{*}{ Three-way } & High CG, High PR & $-.15(.11)$ & \multirow{4}{*}{$.11^{*}(.05)$} & .02 & $(-.0522, .0071)$ \\
\hline & Low CG, High PR & $.45^{* * *}(.09)$ & & $.05^{*}$ & $(.0064, .1016)$ \\
\hline & High CG, Low PR & $-.01(.12)$ & & .00 & $(-.0312, .0290)$ \\
\hline & Low CG, Low PR & $-.10(.10)$ & & -.01 & $(-.0417, .0109)$ \\
\hline
\end{tabular}

Note:

a. $N=376$ dyads from 120 individuals within 30 work groups. ${ }^{*} p \leq .05 ; * * p \leq .01 ;{ }^{* * *} p \leq .001$ two-tailed

b. High PR = one standard deviation above the mean value of perceived rivalry; Low $\mathrm{PR}=$ one standard deviation below the mean value of perceived rivalry. High CG= one standard deviation above the mean value of cooperative goals; low $\mathrm{CG}=$ one standard deviation below the mean value of cooperative goals.

c. Pxm: path from A's observed abusive supervision of B to A's schadenfreude at B.

Pmy: path from A's schadenfreude at B to A's deviance towards B.

d. Based on 10,000 Monte Carlo samples (Selig and Preacher 2008). 
Table 5 Means, Standard Deviations, and Correlations among Variables (Study 3)

\begin{tabular}{|c|c|c|c|c|c|c|c|c|c|c|c|c|c|c|c|c|}
\hline & & Mean & S.D. & 1 & 2 & 3 & 4 & 5 & 6 & 7 & 8 & 9 & 10 & 11 & 12 & 13 \\
\hline & Dyadic level variables & & & & & & & & & & & & & & & \\
\hline 1 & Interpersonal dislike & 1.74 & .98 & -- & .60 & .32 & .39 & .36 & .45 & .18 & .18 & .16 & -- & -- & -- & -- \\
\hline 2 & Moral exclusion belief & 1.63 & .87 & .73 & -- & .42 & .53 & .29 & .62 & .23 & .21 & .20 & -- & -- & -- & -- \\
\hline 3 & Contentment & 2.23 & 1.40 & .36 & .43 & -- & .43 & .22 & .64 & .14 & .12 & .10 & -- & -- & -- & -- \\
\hline 4 & Observed AS & 1.92 & .94 & .46 & .54 & .45 & -- & .31 & .54 & .21 & .20 & .19 & -- & -- & -- & -- \\
\hline 5 & Perceived rivalry & 2.42 & 1.32 & .46 & .40 & .25 & .41 & -- & .31 & .16 & .13 & .12 & -- & -- & -- & -- \\
\hline 6 & Schadenfreude & 1.67 & .91 & .52 & .65 & .67 & .61 & .36 & -- & .18 & .17 & .14 & -- & -- & -- & -- \\
\hline 7 & Undermining & 2.25 & 1.39 & .25 & .26 & .17 & .27 & .23 & .25 & -- & .92 & .88 & -- & -- & -- & -- \\
\hline 8 & Incivility & 2.19 & 1.32 & .24 & .22 & .14 & .23 & .17 & .17 & .94 & -- & .93 & -- & -- & -- & -- \\
\hline \multirow[t]{2}{*}{9} & Interpersonal deviance & 2.11 & 1.30 & .25 & .21 & .14 & .23 & .17 & .15 & .93 & .97 & -- & -- & -- & -- & -- \\
\hline & Individual level variables & & & & & & & & & & & & -- & -- & -- & -- \\
\hline 10 & BJW & 5.03 & 1.05 & -.17 & -.19 & -.13 & -.23 & -.10 & -.14 & -.17 & -.17 & -.18 & & -- & -- & -- \\
\hline 11 & Moral identity & 5.54 & .85 & -.2 & -.27 & -.17 & -.26 & -.16 & -.21 & -.24 & -.21 & -.22 & .47 & -- & -- & - \\
\hline 12 & $\mathrm{LMX}$ & 3.69 & .63 & -.2 & -.24 & -.14 & -.30 & -.18 & -.23 & -.11 & -.14 & -.15 & .34 & .30 & -- & -- \\
\hline 13 & Group cooperative goal & 4.44 & .60 & -.17 & -.16 & -.12 & -.16 & -.17 & -.19 & -.41 & -.44 & -.43 & .20 & .25 & .26 & - \\
\hline
\end{tabular}

Note. $\mathrm{N}=1669$ dyads from 395 employees. Correlations stronger than or equal to \pm .12 are significant at $\mathrm{p}<.05$. Correlations stronger than or equal to \pm .16 are significant at $\mathrm{p}<.01$. Correlations stronger than \pm .17 are significant at $\mathrm{p}<.001$. Correlations at dyadic level appear above the diagonal; correlations at individual level appear below the diagonal (dyadic level variables were aggregated to individual level to correlate with individual level variable);

Group cooperative goals were reported at individual level; all the other variables were reported at dyadic level.

${ }^{\mathrm{a}} \mathrm{AS}$ indicates abusive supervision. 
Table 6 Results of Social Relation Model Analyses on Schadenfreude (Study 3)

\begin{tabular}{|c|c|c|c|c|c|c|c|c|c|}
\hline \multirow{3}{*}{\multicolumn{2}{|c|}{ Steps and Variables }} & \multicolumn{8}{|c|}{ Schadenfreude } \\
\hline & & \multicolumn{2}{|c|}{ Model 1} & \multicolumn{2}{|c|}{ Model 2} & \multicolumn{2}{|c|}{ Model 3} & \multicolumn{2}{|c|}{ Model 4} \\
\hline & & $\beta$ & SE & $\beta$ & SE & $\beta$ & $\mathrm{SE}$ & $\beta$ & SE \\
\hline \multicolumn{10}{|c|}{ Control variables (individual level) } \\
\hline 1 & BJW & .02 & .03 & .02 & .03 & .02 & .03 & .01 & .03 \\
\hline 2 & Moral identity & -.02 & .04 & -.02 & .04 & -.02 & .04 & -.02 & .03 \\
\hline 3 & LMX & $-.08 \dagger$ & .04 & $-.09^{*}$ & .04 & $-.09^{*}$ & .04 & $-.08^{*}$ & .04 \\
\hline \multicolumn{10}{|c|}{ Control variables (dyadic level) } \\
\hline 4 & Interpersonal dislike & $.03^{*}$ & .02 & $.05^{* *}$ & .02 & $.05^{* *}$ & .02 & $.05^{* *}$ & .02 \\
\hline 5 & Contentment & $.23^{* * *}$ & .01 & $.23^{* * *}$ & .01 & $.23^{* * *}$ & .01 & $.23^{* * *}$ & .01 \\
\hline 6 & Moral exclusion belief (belief) & $.23^{* * *}$ & .03 & $.23^{* * *}$ & .03 & $.23^{* * *}$ & .03 & $.23^{* * *}$ & .03 \\
\hline \multicolumn{10}{|c|}{ Independent variables (dyadic level) } \\
\hline 7 & Observed abusive supervision (AS) & $.09^{* * *}$ & .02 & $.07^{* * *}$ & .02 & $.07^{* * *}$ & .02 & $.06^{* *}$ & .02 \\
\hline & Perceived rivalry (PR) & $.06^{* * *}$ & .01 & $.06^{* * *}$ & .01 & $.05^{* * *}$ & .01 & $.05^{* * *}$ & .01 \\
\hline \multicolumn{10}{|c|}{ Independent variable (group level) } \\
\hline & Cooperative goal (CG) & $-.12^{\dagger}$ & .07 & -.10 & .07 & -.09 & .07 & -.06 & .07 \\
\hline \multicolumn{10}{|c|}{ Two-way Interaction } \\
\hline & AS*belief (control) & $.05^{* * *}$ & .01 & .01 & .01 & .01 & .01 & .01 & .01 \\
\hline 11 & AS*PR & & & $.09^{* * * *}$ & .01 & $.09^{* * *}$ & .01 & $.09^{* * *}$ & .01 \\
\hline 12 & $\mathrm{AS} * \mathrm{CG}$ & & & $-.07^{*}$ & .03 & -.06 & .04 & -.03 & .04 \\
\hline 13 & $\mathrm{CG} * \mathrm{PR}$ & & & & & $-.06^{*}$ & .03 & $-.06^{*}$ & .03 \\
\hline \multicolumn{10}{|c|}{ Three-way Interaction } \\
\hline & $\mathrm{AS} * \mathrm{PR} * \mathrm{CG}$ & & & & & & & $-.07^{* *}$ & .02 \\
\hline & $\chi^{2}$ & \multicolumn{2}{|c|}{2298.09} & \multicolumn{2}{|c|}{2235.72} & \multicolumn{2}{|c|}{2235.753} & \multicolumn{2}{|c|}{2231.068} \\
\hline & $\Delta \chi^{2}(\mathrm{df})$ & \multicolumn{2}{|c|}{$508.14(10)^{* * *}$} & \multicolumn{2}{|c|}{$63.37 * * *(2)$} & \multicolumn{2}{|c|}{$.04(1)$} & \multicolumn{2}{|c|}{$4.69 *(1)$} \\
\hline
\end{tabular}

Note: $\mathrm{N}=1669$ dyads from 395 employees within 90 work groups. $\dagger p<.10,{ }^{*} p<.05$, ** $p<.01$, *** $p<.001$. 
Table 7 Results of Social Relation Model Analyses (Study 3)

\begin{tabular}{|c|c|c|c|c|c|c|c|c|c|c|c|c|c|}
\hline \multirow{3}{*}{\multicolumn{2}{|c|}{$\begin{array}{l}\text { Steps and Variables } \\
\text { Control variables (individual level) }\end{array}$}} & \multicolumn{4}{|c|}{ Undermining } & \multicolumn{4}{|c|}{ Incivility } & \multicolumn{4}{|c|}{ Interpersonal deviance } \\
\hline & & \multicolumn{2}{|c|}{ Model 1} & \multicolumn{2}{|c|}{ Model 2} & \multicolumn{2}{|c|}{ Model 3} & \multicolumn{2}{|c|}{ Model 4} & \multirow{2}{*}{$\frac{\text { Model } 5}{\beta}$} & \multicolumn{3}{|c|}{ Model 6} \\
\hline & & $\beta$ & SE & $\beta$ & $\mathrm{SE}$ & $\beta$ & SE & $\beta$ & $\mathrm{SE}$ & & $\mathrm{SE}$ & $\beta$ & SE \\
\hline 1 & BJW & -.02 & .06 & -.02 & .06 & -.02 & .06 & -.01 & .06 & -.02 & .06 & -.02 & .06 \\
\hline 2 & Moral identity & -.09 & .08 & -.09 & .08 & -.05 & .08 & -.05 & .08 & -.09 & .08 & -.09 & .08 \\
\hline 3 & LMX & .05 & .09 & .05 & .09 & -.05 & .09 & -.05 & .09 & -.08 & .09 & -.08 & .09 \\
\hline \multicolumn{14}{|c|}{ Control variables (dyadic level) } \\
\hline 4 & Interpersonal dislike & $.06^{* *}$ & .02 & $.06^{* *}$ & .02 & $.06^{* *}$ & .02 & $.06^{* *}$ & .02 & -.01 & .02 & -.01 & .02 \\
\hline 5 & Contentment & .02 & .02 & .02 & .02 & .02 & .02 & .02 & .02 & .01 & .02 & .01 & .02 \\
\hline 6 & Moral exclusion belief (belief) & $.10^{*}$ & .04 & $.10^{*}$ & .04 & .05 & .03 & .05 & .03 & $.07^{*}$ & .03 & $.07^{*}$ & .03 \\
\hline \multicolumn{14}{|c|}{ Independent Variables (dyadic level) } \\
\hline 7 & Observed abusive supervision (AS) & $.06^{\dagger}$ & .03 & $.06^{\dagger}$ & .03 & .02 & .03 & .02 & .03 & .01 & .03 & .03 & .03 \\
\hline 8 & Perceived rivalry (PR) & -.01 & .02 & -.01 & .02 & $-.03^{*}$ & .02 & $-.03^{*}$ & .02 & -.01 & .01 & -.01 & .01 \\
\hline \multicolumn{14}{|c|}{ Independent Variable (group level) } \\
\hline 9 & Cooperative goal (CG) & $-.99^{* * *}$ & .20 & $-.99^{* * *}$ & .20 & $-1.02^{* * *}$ & .19 & $-1.02^{* * *}$ & .19 & $-.95^{* * *}$ & .19 & $-.98^{* * *}$ & .18 \\
\hline \multicolumn{14}{|c|}{ Two-way Interaction } \\
\hline 10 & AS*belief & .00 & .02 & .00 & .02 & -.01 & .02 & -.01 & .02 & $.04^{*}$ & .02 & $.04^{*}$ & .02 \\
\hline 11 & AS*PR & .02 & .02 & .02 & .02 & -.01 & .01 & -.01 & .01 & -.02 & .01 & -.02 & .01 \\
\hline 12 & $\mathrm{AS} * \mathrm{CG}$ & .01 & .06 & .00 & .07 & -.05 & .06 & -.06 & .06 & .06 & .05 & .03 & .05 \\
\hline 13 & $\mathrm{CG}^{*} \mathrm{PR}$ & & & -.02 & .04 & & & .04 & .04 & & & .03 & .03 \\
\hline \multicolumn{14}{|c|}{ Three-way Interaction } \\
\hline & $\mathrm{AS} * \mathrm{PR} * \mathrm{CG}$ & & & .02 & .04 & & & .00 & .03 & & & $.08^{* *}$ & .03 \\
\hline $\mathrm{Mec}$ & diator: Schadenfreude & $.13^{* * *}$ & .04 & $.14^{* * *}$ & .04 & $.14^{* * *}$ & .03 & $.14^{* * *}$ & .03 & $.09^{* *}$ & .03 & $.10^{* *}$ & .03 \\
\hline & $\chi^{2}$ & \multicolumn{2}{|c|}{3598.72} & \multicolumn{2}{|c|}{3607.52} & \multicolumn{2}{|c|}{3171.70} & \multicolumn{2}{|c|}{3180.41} & \multicolumn{2}{|l|}{2999.98} & \multicolumn{2}{|c|}{3000.47} \\
\hline & $\Delta \chi^{2}(\mathrm{df})$ & \multicolumn{2}{|c|}{$46.71^{* * *}(1)$} & \multicolumn{2}{|c|}{$46.75^{* * *}(1)$} & \multicolumn{2}{|c|}{$53.48^{* * *}(1)$} & \multicolumn{2}{|c|}{$53.88^{* * *}(1)$} & \multicolumn{2}{|c|}{$46.67^{* * *}(1)$} & \multicolumn{2}{|c|}{$48.32^{* * *}(1)$} \\
\hline
\end{tabular}

Note: $\mathrm{N}=1669$ dyads from 395 employees within 90 work groups. $\dagger p<.10,{ }^{*} p<.05,{ }^{* *} p<.01,{ }^{* * *} p<.001$. 
Table 8 Results of the Moderated Path Analysis ${ }^{a}$ (Study 3)

\begin{tabular}{|c|c|c|c|c|c|c|c|c|c|c|c|}
\hline & & \multicolumn{5}{|c|}{ Undermining } & \multicolumn{3}{|l|}{ Incivility } & \multicolumn{2}{|c|}{ Interpersonal deviance } \\
\hline \multicolumn{2}{|r|}{ Conditions $^{\mathrm{b}}$} & \multirow{2}{*}{$\begin{array}{l}\mathrm{Pxm}^{\mathrm{C}} \\
\text { Estimate }\end{array}$} & \multirow{2}{*}{$\begin{array}{c}\text { Pmy } \\
\text { Estimate }\end{array}$} & \multicolumn{2}{|c|}{ Indirect effect } & \multirow{2}{*}{$\begin{array}{c}\text { Pmy } \\
\text { Estimate }\end{array}$} & \multicolumn{2}{|l|}{ Indirect effect } & \multirow{2}{*}{$\begin{array}{c}\text { Pmy } \\
\text { Estminate }\end{array}$} & \multicolumn{2}{|c|}{ Indirect effect } \\
\hline & & & & PxmXPmy 1 & $\begin{array}{l}\text { 95\% confidence } \\
\text { interval }^{\mathrm{d}}\end{array}$ & & PxmXPmy & $\begin{array}{l}95 \% \text { confidence } \\
\text { interval }\end{array}$ & & PxmXPmy & $\begin{array}{l}\text { 95\% confidence } \\
\text { interval }\end{array}$ \\
\hline \multirow{2}{*}{$\begin{array}{l}\text { Two- } \\
\text { way }\end{array}$} & High PR & $.17^{* * *}(.02)$ & \multirow[b]{2}{*}{$.13^{* * *}(.04)$} & $.02^{*}$ & $(.0085, .0371)$ & \multirow[b]{2}{*}{$.14^{* * * *}(.03)$} & $.03^{*}$ & $(.0132, .0359)$ & \multirow[b]{2}{*}{$.09^{* *}(.03)$} & $.02^{*}$ & $(.0052, .0265)$ \\
\hline & Low PR & $-.02(.02)$ & & -.00 & $(-.0009, .0026)$ & & -.00 & $(-.0089, .0027)$ & & -.00 & $(-.0062, .0017)$ \\
\hline \multirow{4}{*}{$\begin{array}{l}\text { Three- } \\
\text { way }\end{array}$} & High CG, High PR & $.06(.05)$ & \multirow{4}{*}{$.14^{* * * *}(.04)$} & .00 & $(-.0053, .0253)$ & \multirow{4}{*}{$.14^{* * *}(.03)$} & .01 & $(-.0053, .0241)$ & \multirow{4}{*}{$.10^{* *}(.03)$} & .01 & $(-.0037, .0181)$ \\
\hline & Low CG, High PR & $.25^{* * *}(.04)$ & & $.04^{*}$ & $(.0142, .0597)$ & & $.04^{*}$ & $(.0180, .0552)$ & & $.03^{*}$ & $(.0094, .0432)$ \\
\hline & High CG, Low PR & $.01(.05)$ & & .00 & $(-.0129, .0165)$ & & .00 & $(-.0127, .0161)$ & & .00 & $(-.0093, .0119)$ \\
\hline & Low CG, Low PR & $-.06(.06)$ & & -.01 & $(-.0280, .0078)$ & & -.01 & $(-.0268, .0085)$ & & -.01 & $(-.0202, .0058)$ \\
\hline
\end{tabular}

a. $N=1669$ dyads from 395 individuals within 90 work groups. ${ }^{*} p \leq .05 ; * * p \leq .01 ;{ }^{* * *} p \leq .001$ two-tailed

b. High PR = one standard deviation above the mean value of perceived rivalry; Low PR = one standard deviation below the mean value of perceived rivalry. High $\mathrm{CG}=$ one standard deviation above the mean value of cooperative goals; low $\mathrm{CG}=$ one standard deviation below the mean value of cooperative goals.

c. Pxm: path from A's observed abusive supervision of B to A's schadenfreude at B.

Pmy: path from A's schadenfreude at B to A's deviance towards B.

d. Based on 10,000 Monte Carlo samples (Selig and Preacher 2008). 
Figure 1 Hypothesized Model

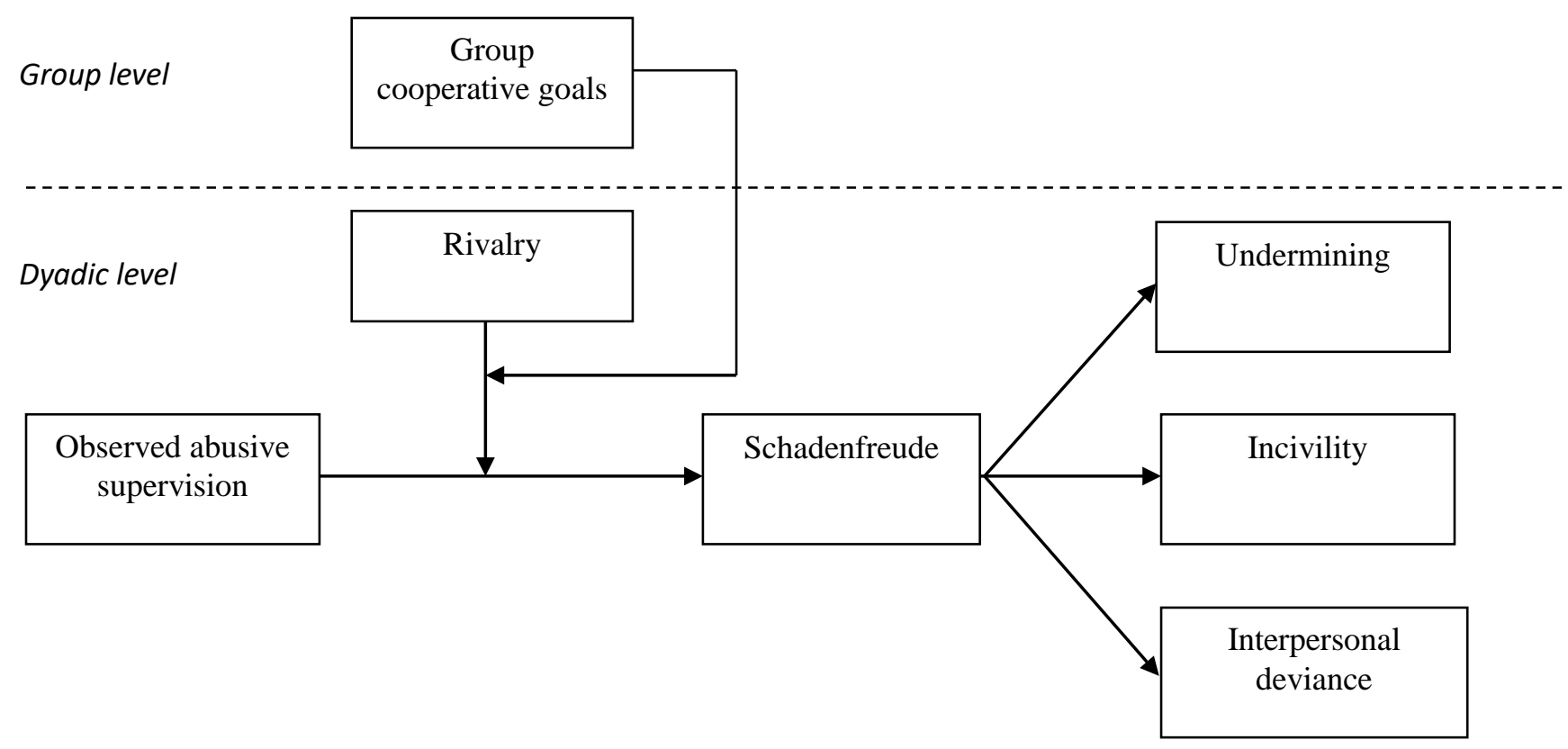


Figure 2 The Interactive Effect of Observed Abusive Supervision and Perceived Rivalry on Observers' Schadenfreude (Study 1)

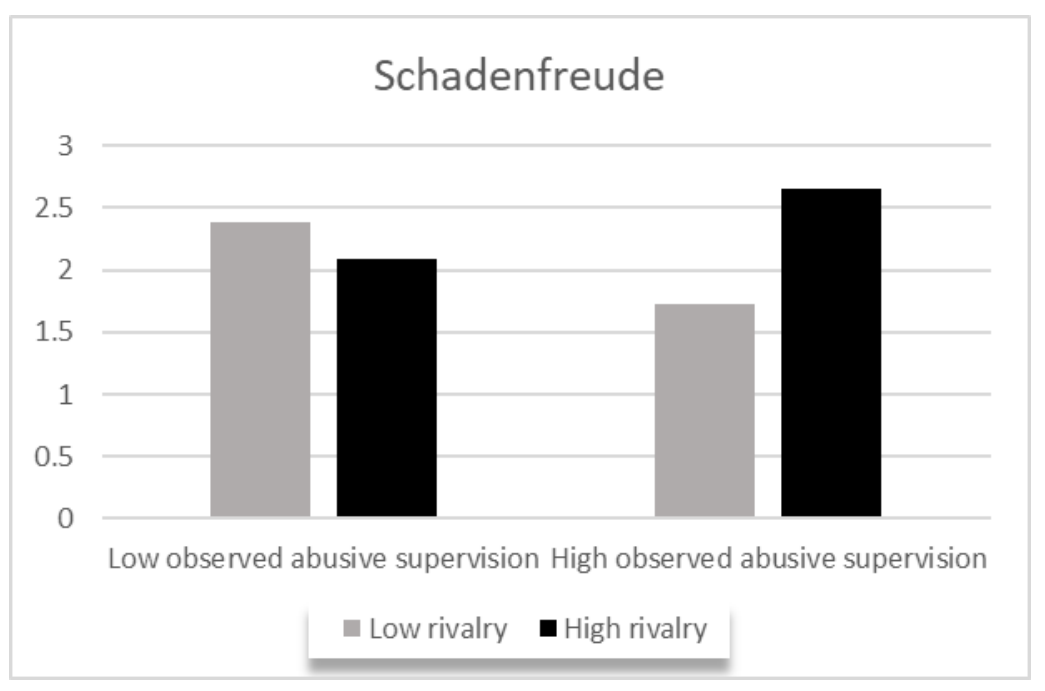

Figure 3 The Interactive Effect of Observed Abusive Supervision and Perceived Rivalry on Observers' Schadenfreude (Study 2)
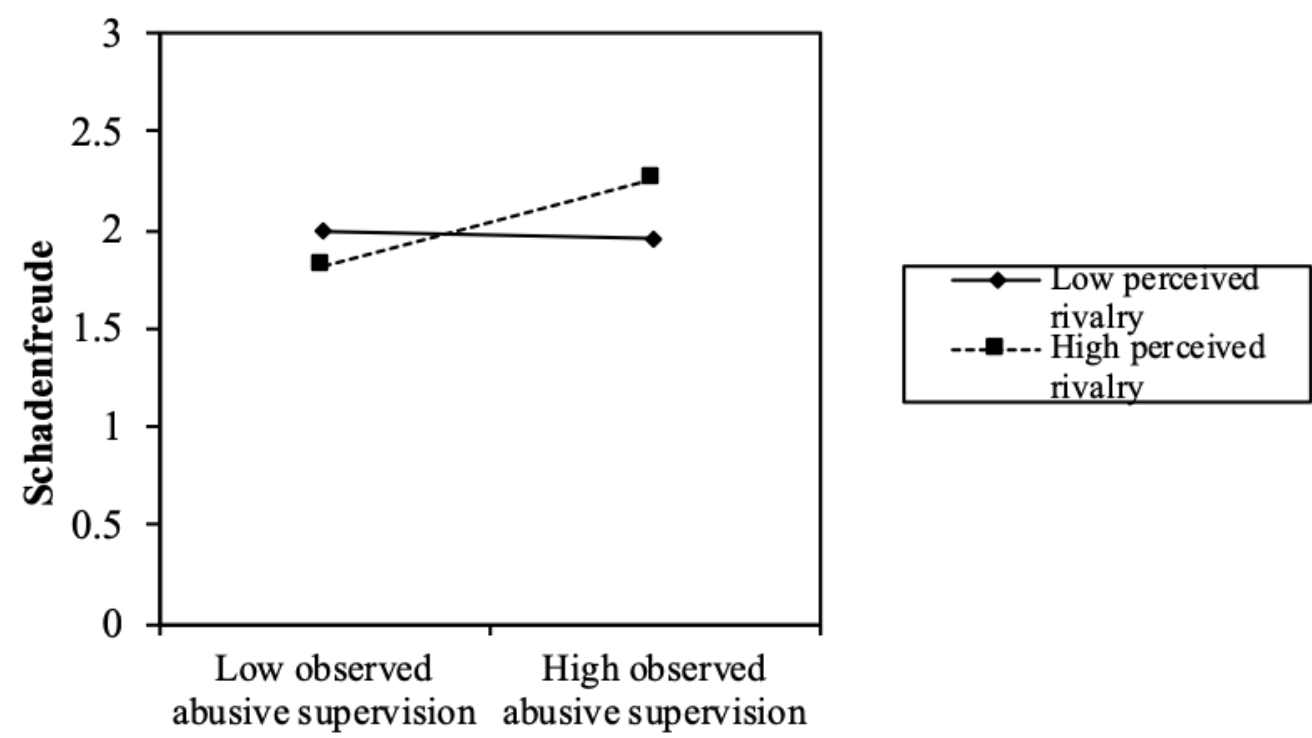
Figure 4 Three-way Interactive Effect of Observed Abusive Supervision, Perceived Rivalry, and Group Cooperative Goals on Observers' Schadenfreude (Study 2)

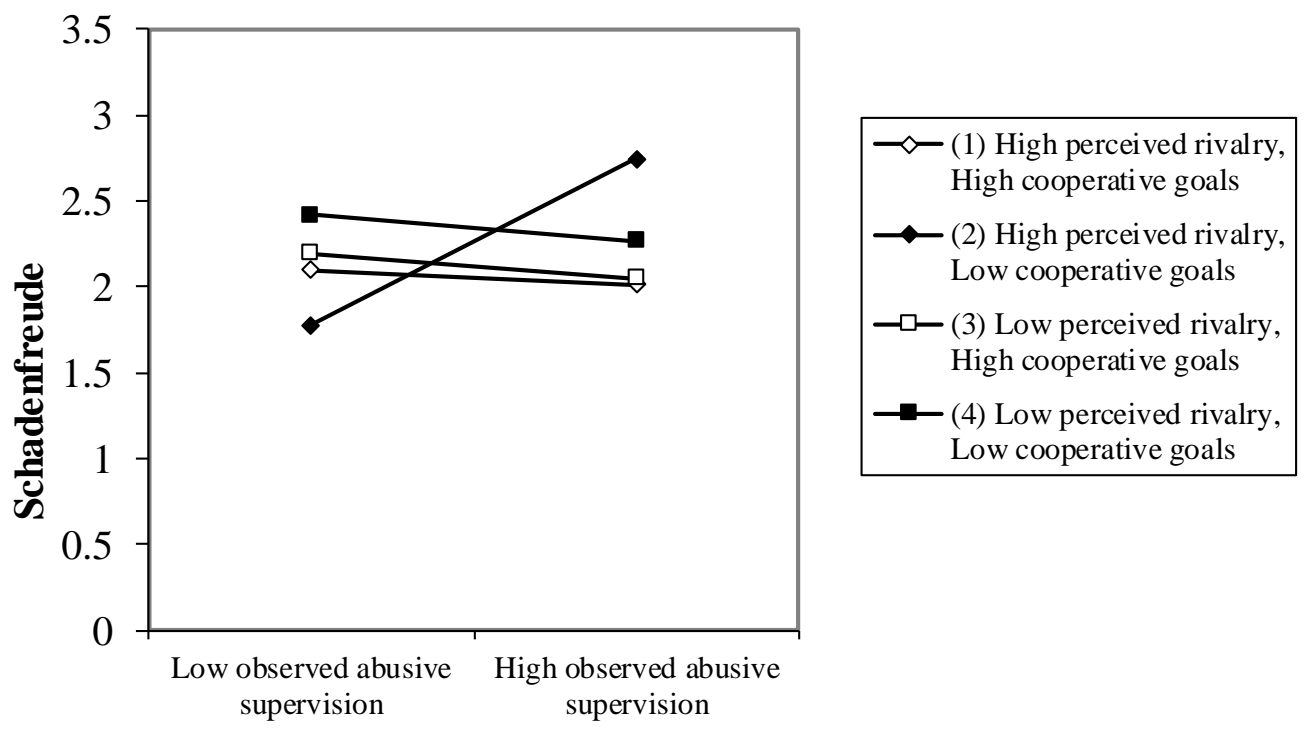

Figure 5 The Interactive Effect of Observed Abusive Supervision and Perceived Rivalry on Observers' Schadenfreude (Study 3)

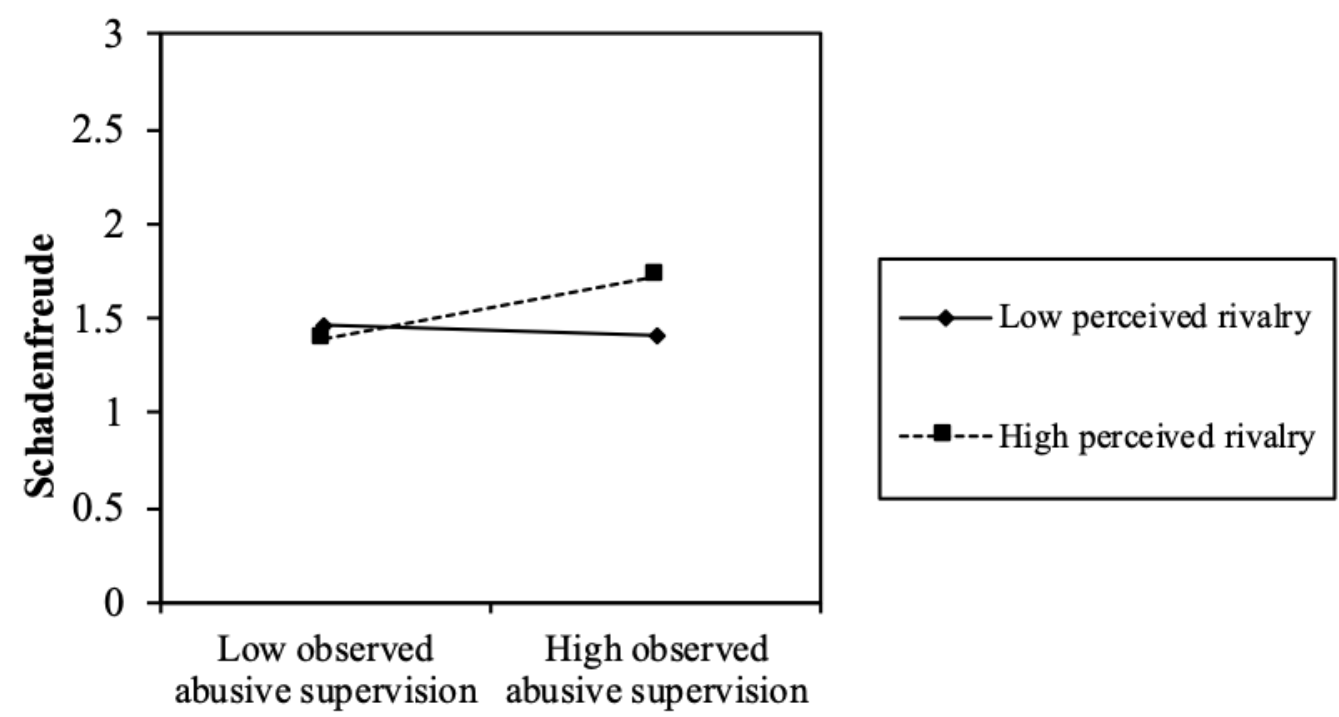


Figure 6 Three-way Interactive Effect of Observed Abusive Supervision, Perceived Rivalry, and Group Cooperative Goals on Observers' Schadenfreude (Study 3)

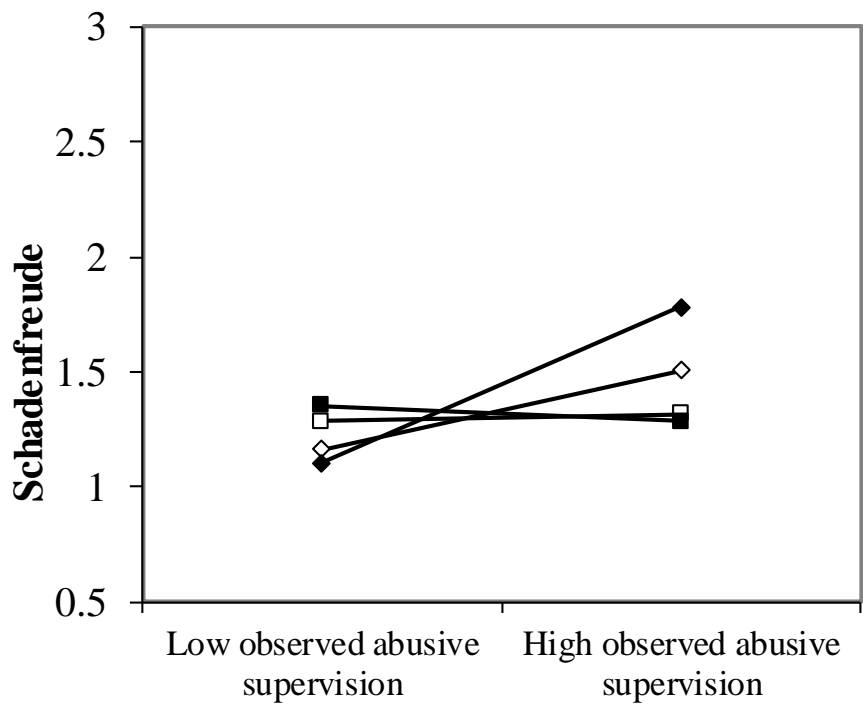

$\prec$ (1) High perceived rivalry, High cooperative goal

$\neg$ (2) High perceived rivalry, Low cooperative goal

$\longrightarrow \square$ (3) Low perceived rivalry, High cooperative goal

$\rightarrow$ (4) Low perceived rivalry, Low cooperative goal 